\title{
Article
}

\section{Interventions for replacing missing teeth: augmentation procedures of the maxillary sinus}

Esposito, Marco, Grusovin, Maria Gabriella, Rees, Jonathan, Karasoulos, Dimitrios, Felice, Pietro, Alissa, Rami, Worthington, Helen V, Coulthard, Paul and Esposito, Marco

Available at https://clok.uclan.ac.uk/7038/

Esposito, Marco, Grusovin, Maria Gabriella, Rees, Jonathan, Karasoulos, Dimitrios, Felice, Pietro, Alissa, Rami, Worthington, Helen V, Coulthard, Paul and Esposito, Marco (2010) Interventions for replacing missing teeth: augmentation procedures of the maxillary sinus. Cochrane database of systematic reviews, 2010 (3). pp. 1-40. ISSN 1469493X

It is advisable to refer to the publisher's version if you intend to cite from the work. http://dx.doi.org/10.1002/14651858.CD008397

For more information about UCLan's research in this area go to

http://www.uclan.ac.uk/researchgroups/ and search for < name of research Group>.

For information about Research generally at UCLan please go to http://www.uclan.ac.uk/research/

All outputs in CLoK are protected by Intellectual Property Rights law, including Copyright law. Copyright, IPR and Moral Rights for the works on this site are retained by the individual authors and/or other copyright owners. Terms and conditions for use of this material are defined in the policies page.

\section{CLoK}

Central Lancashire online Knowledge www.clok.uclan.ac.uk

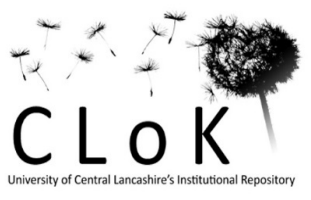




\section{Interventions for replacing missing teeth: augmentation procedures of the maxillary sinus (Review)}

Esposito M, Grusovin MG, Rees J, Karasoulos D, Felice P, Alissa R, Worthington HV, Coulthard P

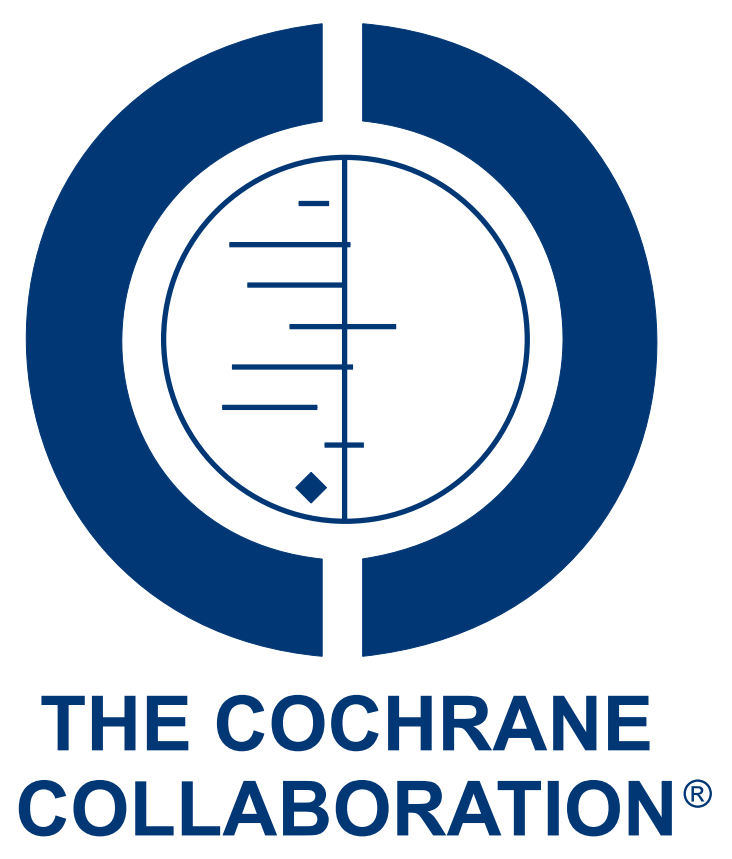

This is a reprint of a Cochrane review, prepared and maintained by The Cochrane Collaboration and published in The Cochrane Library 2010, Issue 4

http://www.thecochranelibrary.com

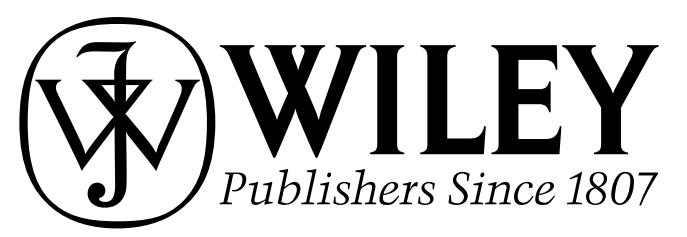

Interventions for replacing missing teeth: augmentation procedures of the maxillary sinus (Review) Copyright $\odot 2010$ The Cochrane Collaboration. Published by John Wiley \& Sons, Ltd. 
TABLE OF CONTENTS

HEADER . . . . . . . . . . . . . . . . . . . . . . . . . . . . . . . . . . . . 1

ABSTRACT . . . . . . . . . . . . . . . . . . . . . . . . . . . . . . . . . . . . . . . . . . . . . . .

PLAIN LANGUAGE SUMMARY . . . . . . . . . . . . . . . . . . . . . . . . . . . . . . . . . . . .

SUMMARY OF FINDINGS FOR THE MAIN COMPARISON $\quad$. . . . . . . . . . . . . . . . . . . . . . . . . .

BACKGROUND . . . . . . . . . . . . . . . . . . . . . . . . . . . . . . . . . . . . . . . . . . 5

OBJECTIVES . . . . . . . . . . . . . . . . . . . . . . . . . . . . . . . . . . . . . . . . . . . .

METHODS . . . . . . . . . . . . . . . . . . . . . . . . . . . . . . . . . . . . . . . . .

RESULTS . . . . . . . . . . . . . . . . . . . . . . . . . . . . . . . . . . . . . . . 9

Figure 1. . . . . . . . . . . . . . . . . . . . . . . . . . . . . . . . . . . . . .

DISCUSSION . . . . . . . . . . . . . . . . . . . . . . . . . . . . . . . . . . . . . . . . .

AUTHORS' CONCLUSIONS . . . . . . . . . . . . . . . . . . . . . . . . . . . . . . . . . . .

ACKNOWLEDGEMENTS . . . . . . . . . . . . . . . . . . . . . . . . . . . . . . . . . . .

REFERENCES . . . . . . . . . . . . . . . . . . . . . . . . . . . . . . . . . . . . . 18

CHARACTERISTICS OF STUDIES . . . . . . . . . . . . . . . . . . . . . . . . . . . . . . 22

Interventions for replacing missing teeth: augmentation procedures of the maxillary sinus (Review)

Copyright $\odot 2010$ The Cochrane Collaboration. Published by John Wiley \& Sons, Ltd. 


\title{
[Intervention Review] \\ Interventions for replacing missing teeth: augmentation procedures of the maxillary sinus
}

\author{
Marco Esposito ${ }^{1}$, Maria Gabriella Grusovin ${ }^{1}$, Jonathan Rees ${ }^{1}$, Dimitrios Karasoulos ${ }^{1}$, Pietro Felice ${ }^{2}$, Rami Alissa ${ }^{1}$, Helen V Worthing- \\ ton $^{3}$, Paul Coulthard ${ }^{1}$ \\ ${ }^{1}$ Department of Oral and Maxillofacial Surgery, School of Dentistry, The University of Manchester, Manchester, UK. ${ }^{2}$ Department of \\ Oral and Dental Sciences, University of Bologna, Bologna, Italy. ${ }^{3}$ Cochrane Oral Health Group, School of Dentistry, The University \\ of Manchester, Manchester, UK
}

Contact address: Marco Esposito, Department of Oral and Maxillofacial Surgery, School of Dentistry, The University of Manchester, Higher Cambridge Street, Manchester, M15 6FH, UK. espositomarco@hotmail.com. marco.esposito@manchester.ac.uk.

Editorial group: Cochrane Oral Health Group.

Publication status and date: Edited (no change to conclusions), published in Issue 4, 2010.

Review content assessed as up-to-date: 6 January 2010.

Citation: Esposito M, Grusovin MG, Rees J, Karasoulos D, Felice P, Alissa R, Worthington HV, Coulthard P. Interventions for replacing missing teeth: augmentation procedures of the maxillary sinus. Cochrane Database of Systematic Reviews 2010, Issue 3. Art. No.: CD008397. DOI: 10.1002/14651858.CD008397.

Copyright (C) 2010 The Cochrane Collaboration. Published by John Wiley \& Sons, Ltd.

\begin{abstract}
A B S T R A C T
Background

Insufficient bone volume is a common problem encountered in the rehabilitation of the edentulous posterior maxillae with implantsupported prostheses. Bone volume is limited by the presence of the maxillary sinus together with loss of alveolar bone height. Sinus lift procedures increase bone volume by augmenting the sinus cavity with autogenous bone and/or commercially available biomaterials.
\end{abstract}

\section{Objectives}

To determine whether and when augmentation of the maxillary sinus are necessary and which are the most effective augmentation techniques for rehabilitating patients with implant-supported prostheses.

\section{Search methods}

The Cochrane Oral Health Group's Trials Register, CENTRAL, MEDLINE and EMBASE were searched on 7th January 2010. Several dental journals were handsearched. The bibliographies of review articles were checked, and personal references were searched. More than 55 implant manufacturing companies were also contacted.

\section{Selection criteria}

Randomised controlled trials (RCTs) of different techniques and materials for augmenting the maxillary sinus for rehabilitation with dental implants reporting the outcome of implant success/failure at least to abutment connection.

\section{Data collection and analysis}

Screening of eligible studies, assessment of the methodological quality of the trials and data extraction were conducted independently and in duplicate. Authors were contacted for any missing information. Results were expressed as random-effects models using mean differences for continuous outcomes and odds ratios for dichotomous outcomes with $95 \%$ confidence intervals. The statistical unit of the analysis was the patient.

Interventions for replacing missing teeth: augmentation procedures of the maxillary sinus (Review)

Copyright @ 2010 The Cochrane Collaboration. Published by John Wiley \& Sons, Ltd. 


\section{Main results}

Ten RCTs out of 29 met the inclusion criteria. One trial of 15 patients evaluated implants $5 \mathrm{~mm}$ long with 6 mm diameter as an alternative to sinus lift in bone with a residual height of 4 to $6 \mathrm{~mm}$. Nine trials with 235 patients compared different sinus lift techniques; of these four trials (114 patients) evaluated the efficacy of platelet-rich plasma (PRP). Due to the variety of techniques evaluated, metaanalysis was only possible of use of PRP for implant failure (two trials) and complications (three trials). No statistically significant difference was observed.

\section{Authors' conclusions}

Conclusions are based on few small trials, with short follow-up, and judged to be at high risk of bias. Therefore conclusions should be viewed as preliminary and interpreted with great caution. It is still unclear when sinus lift procedures are needed. $5 \mathrm{~mm}$ short implants can be successfully loaded in maxillary bone with a residual height of 4 to $6 \mathrm{~mm}$ but their long-term prognosis is unknown. Elevating the sinus lining in presence of 1 to $5 \mathrm{~mm}$ of residual bone height without the addition of a bone graft may be sufficient to regenerate new bone to allow rehabilitation with implant-supported prostheses. Bone substitutes might be successfully used as replacements for autogenous bone. If the residual alveolar bone height is 3 to $6 \mathrm{~mm}$ a crestal approach to lift the sinus lining, to place $8 \mathrm{~mm}$ implants may lead to fewer complications than a lateral window approach, to place implants at least $10 \mathrm{~mm}$ long. There is no evidence that PRP treatment improves the clinical outcome of sinus lift procedures with autogenous bone or bone substitutes.

\section{PLAIN LANGUAGE SUMMARY}

\section{Interventions for replacing missing teeth: augmentation procedures of the maxillary sinus}

Sufficient bone quantity is required for dental implant placement. Bone quantity towards the back of the upper jaw may be insufficient for dental implant placement because of the presence of the maxillary sinus, a natural cavity within the bone. This cavity may enlarge following tooth loss. There are a number of techniques, termed sinus lift procedures, aimed at increasing bone quantity prior to implant placement. These techniques utilise bone graft material, either the patients own bone (autogenous bone), a range of commercially available materials (biomaterials) or a combination of the two.

Short implants ( 5 to $8 \mathrm{~mm}$ ) may be as effective and cause fewer complications than longer implants placed using a more complex technique. It is not clear that bone graft materials are needed or whether some bone graft materials are more effective than others. Biomaterials might be used in place of autogenous bone. There is no evidence to suggest factors extracted from the patients blood improve bone healing. 


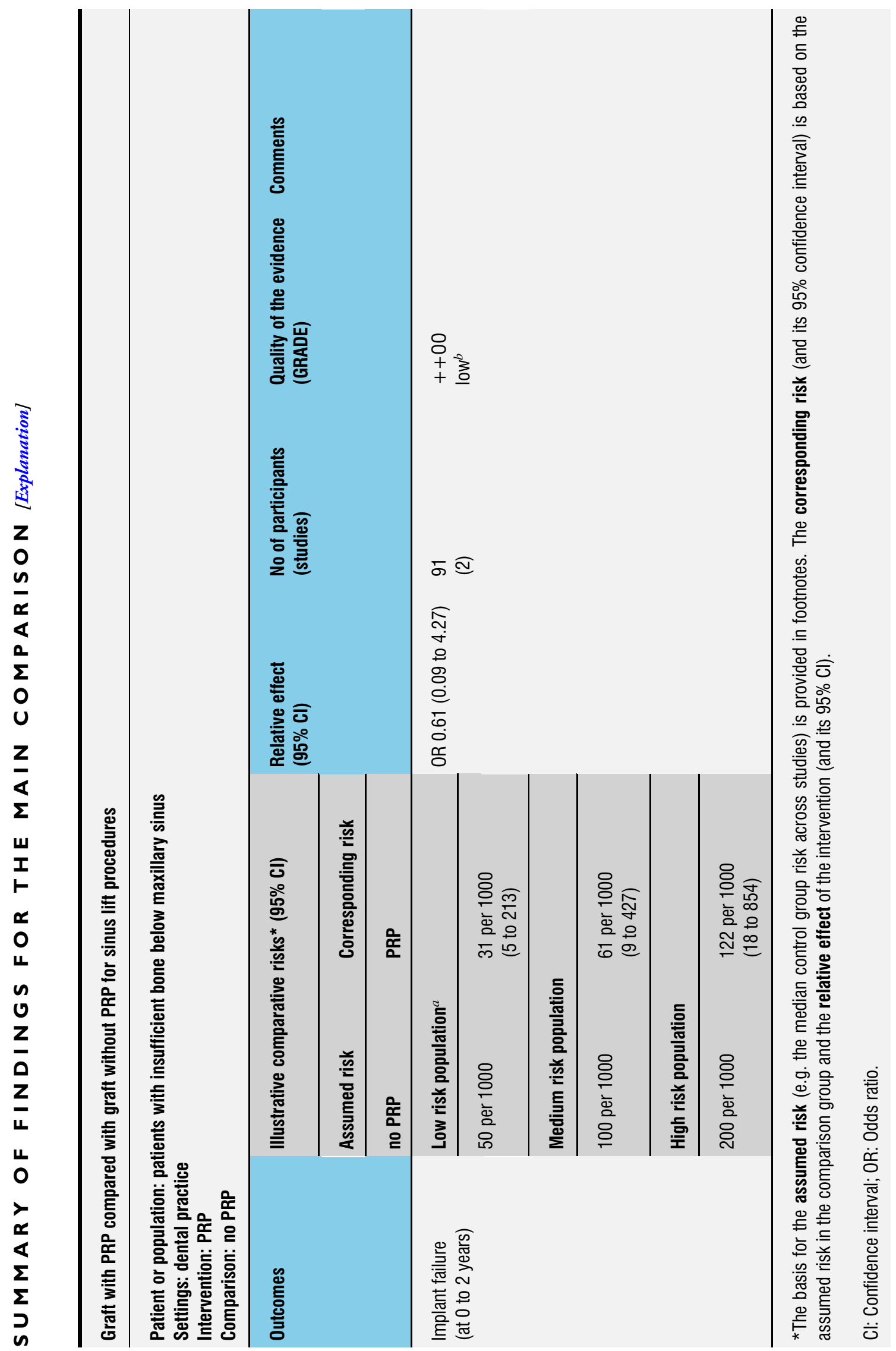

Interventions for replacing missing teeth: augmentation procedures of the maxillary sinus (Review)

Copyright $\odot 2010$ The Cochrane Collaboration. Published by John Wiley \& Sons, Ltd. 


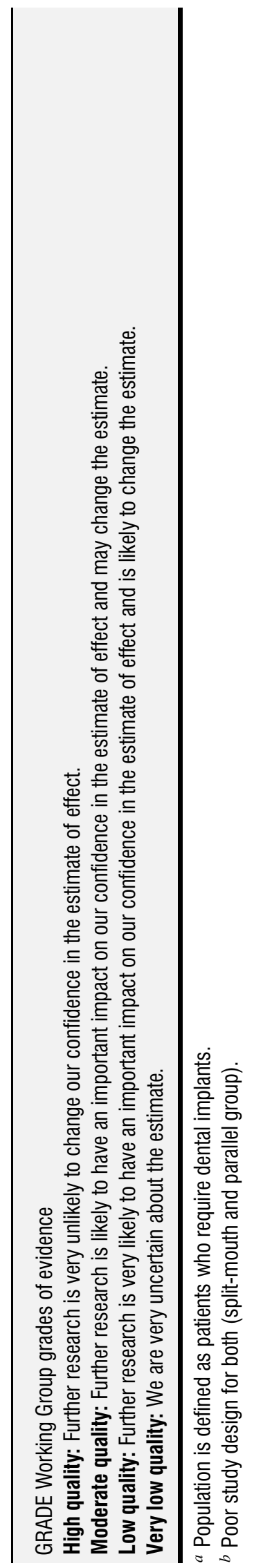

Interventions for replacing missing teeth: augmentation procedures of the maxillary sinus (Review)

Copyright @ 2010 The Cochrane Collaboration. Published by John Wiley \& Sons, Ltd. 


\section{B A C K G R O U N D}

Missing teeth may result in a functional and cosmetic deficit and have traditionally been replaced with dentures or bridges. Dental implants offer an alternative, they are inserted into the jawbones and used to support dental prostheses. Dental implants rely on the maintenance of a direct structural and functional connection between living bone and the implant surface, this is termed osseointegration and was first described by Brånemark (Brånemark 1977). Osseointegration has undoubtedly been one of the most significant scientific breakthroughs in dentistry over the past 40 years.

Insufficient bone volume is a common problem encountered in the rehabilitation of the edentulous posterior maxilla with implantsupported prostheses. The bone available for implant placement may be limited by the presence of the maxillary sinus together with loss of alveolar bone height. Bone volume may be increased by augmentation, commonly the sinus cavity is augmented with autogenous bone or biomaterials or both. Procedures are variously described in the literature as sinus lift, sinus augmentation, sinus floor elevation or augmentation of atrophic maxillary sinus.

Implant placement may be combined with sinus augmentation as a 'one-stage' technique. Alternatively sinus augmentation may be carried out at some time prior to implant placement, as a 'twostage' technique which requires an additional surgical episode.

\section{Techniques of sinus augmentation (sinus lift)}

Boyne described the pre-prosthetic surgical technique of retrograde sinus augmentation, in some cases blade implants were placed (Boyne 1980). The technique required a window to be prepared in the lateral wall of the sinus via a buccal sulcus incision, the mucosal lining was elevated to create a cavity into which particulate bone from the iliac crest was placed and allowed to heal for about 6 months or more before placing the implants.

Tatum described five tissue incisions (crestal, palatal, split thickness palatal, vertical and horizontal vestibular), three types of bone access (crestal, buccal wall and Le Forte I), the use of autogenous bone, allograft and alloplast. In addition Tatum described sinus augmentation and implant placement as a one-stage and a twostage technique (Tatum 1986).

The technique, known as a lateral window sinus lift, is widely used today and is considered reliable particularly when autogenous bone is used (Wallace 2003; Del Fabbro 2004).

Summers described a less invasive one-stage technique for sinus floor elevation with simultaneous implant placement called the osteotome sinus floor elevation. Summers considered necessary at least $6 \mathrm{~mm}$ of residual bone to ensure primary stability of the implant. Concave tipped osteotomes of increasing diameter applied via a crestal approach advanced a mass of bone beyond the level of the original sinus floor, elevating the mucosal lining. Summers combined this procedure with the addition of a bone graft material
(Summers 1994). For cases of less than $6 \mathrm{~mm}$ residual bone height, Summers proposed a two-stage approach. A bone plug is defined with a trephine and displaced superiorly with the use of a broad osteotome. Hydrostatic pressure elevates the mucosal lining of the sinus. The resultant osteotomy is filled with a bone graft material and the implant placed after a period of healing (Summers 1995). Cosci modified the crestal approach technique utilising an atraumatic lifting drill to reduce the risk of perforation of the mucosa lining the sinus using this one-stage technique with as little as 3 $\mathrm{mm}$ of residual bone (Cosci 2000). Bone can be collected with a trephine directly from the osteotomy site to be used as grafting material, a bone substitute can be used or the implant tip can hold up the sinus membrane that will work as a natural barrier for bone regeneration. While the crestal approach is less invasive and is a one-stage technique, there are some disadvantages associated with it. The amount of bone which can be gained using a crestal approach is usually less than that obtained with the lateral window technique, and a minimum of $3 \mathrm{~mm}$ crestal bone height is generally recommended to stabilize the implant at placement (Cosci 2000).

In order to obtain simultaneous vertical bone augmentation with a sinus lift procedure, Cannizzaro proposed a technique that is a combination of a sinus lift and an onlay graft. Implants are placed in the ulna, bone blocks containing the implants are retrieved with a trephine, inserted into the sinus via a crestal approach and left protruding occlusally for some $\mathrm{mm}$ in order to obtain simultaneous vertical bone gain (Cannizzaro 2007).

\section{Materials used in sinus lift procedures}

Autogenous bone has long been considered the gold standard (Palmer 2000). Intra-oral donor sites (chin and ramus) are convenient but yield limited volume. Extra-oral donor sites (iliac crest, tibia, ulna, rib and calvarium) increase surgical complexity and are associated with significant (and underreported) morbidity and scarring. Therefore alternative grafting materials (bone substitutes) have been developed.

Allografts consist of 'same species' tissue. Cadaveric bone is harvested and various techniques (freeze drying and irradiation) reduce antigenicity. The grafts are then sterilised and supplied by specially licensed tissue banks.

Xenografts consist of 'different species' tissue. Anorganic bovine and equine bone predominate. Chemical removal of the organic component creates a mineral scaffold.

Alloplasts are synthetic bone substitutes. There are many types classified in terms of porosity as dense, macro-porous, microporous, and either crystalline or amorphous. The structure influences performance. Some examples are: beta tri-calcium phosphate, bio-active glass, calcium sulphate.

All these graft materials can be delivered in various convenient forms such as bone particles or large blocks, can be mixed with 
autogenous bone and can be very stable over time or highly resorbable, depending on their chemical characteristics.

Urist discovered that cell free, decalcified bone implanted into extra-skeletal sites stimulated new bone formation (Urist 1965). The biologically active molecules responsible belong to the growth factor B family and are called bone morphogenetic proteins (BMPs) (Valentin-Opran 2002). A number have been discovered (growth factors, platelet-rich plasma (PRP), and other molecules) and their use requires a delivery system that mimics the physical properties and release kinetics of bone.

Some authors have proposed sinus augmentation without the use of a graft material, coagulated blood acting as a scaffold for bone formation. Lundgren proposed maintaining a space by suturing the sinus lining to the lateral wall (Lundgren 2004). The implant apex may be used to support the sinus membrane (Nedir 2006; Hatano 2007; Thor 2007; Sohn 2008; Gabbert 2009; Pjetursson 2009). Some bone regeneration does occur as a result of this procedure though the actual clinical benefit remains in doubt since this method has not been evaluated against appropriate control procedures.

\section{Alternative techniques to sinus lift}

There are some alternative techniques to sinus augmentation, which may be possible. Onlay bone grafts may be used for horizontal or vertical augmentation. These procedures are evaluated in another Cochrane systematic review (Esposito 2009).

Implants can also be placed with an angulated direction in order to avoid the maxillary sinus (Aparicio 2001). These implants are called 'tilted' or 'angulated' implants and they can only be used when anatomical conditions permit.

Zygomatic implants offer an alternative to sinus augmentation. Long implants pass through the sinus (Brånemark 2004) or laterally to the sinus into the zygomatic process. Zygomatic implants are evaluated in another Cochrane review (Esposito 2005). In some situations angled implants may be placed into the pterygomaxilla (Graves 1994).

Another alternative to sinus lift procedures is the use of short implants. Current research is focused on evaluating short implants placed without augmentation, offering the opportunity of a less complex, cheaper and faster alternative to augmentation. There are few comparative studies evaluating the efficacy of short implants (Esposito 2009). There is some variation as to the definition of short implants. Implants with lengths of 5 to $8 \mathrm{~mm}$ are currently used, and may be defined as short implants (Renouard 2006), though this is controversial as some authors consider implants of 7 to $10 \mathrm{~mm}$ to be short (das Neves 2006).

A review of longitudinal studies suggested a failure rate of approximately $10 \%$ for implants $7 \mathrm{~mm}$ long (das Neves 2006). However the design of the studies on which this estimate is based suggest that this figure should be viewed with caution as it may represent a gross underestimation. Nevertheless these figures suggest that shorter implants may have a poorer prognosis than longer ones. Since it is commonly believed that shorter implants $(8 \mathrm{~mm}$ or less) have a poorer prognosis than longer implants, clinicians place longer implants if bone allows. When bone height is 5 to $8 \mathrm{~mm}$ clinicians must decide whether to augment or place short implants. It is possible that in the future new and improved implant surface modifications and designs, together with improved surgical techniques may shift the balance in favour of short implants, when the alternative is a more complex augmentation procedure. No reliable evidence of the superiority of currently available surface modifications or designs has been documented so far (Esposito 2007).

Several 'systematic' reviews have been published on the outcome of sinus lifting procedures (Tong 1998; Wallace 2003; Del Fabbro 2004; Emmerich 2005; Aghaloo 2007; Pjetursson 2008; Tan 2008; Nkenke 2009), however, since those findings were not based on the most reliable clinical studies, a systematic review based on the most reliable evidence would be useful to summarise the current scientific knowledge.

\section{O B JE C T IVES}

\section{General objectives}

To test the null hypothesis that there is no difference in the outcomes of implant success, function, complication rate and patient satisfaction as a result of bone augmentation, compared to no augmentation. Furthermore there is no difference between different maxillary sinus lift techniques for dental implant treatment with regard to these outcomes.

\section{Specific objectives}

(A) To test whether and when sinus lift procedures are necessary.

(B) To test which is the most effective augmentation technique for sinus lift.

\section{METHODS}

\section{Criteria for considering studies for this review}

\section{Types of studies}

Randomised controlled clinical trials (RCTs) including splitmouth studies. 


\section{Types of participants}

Patients with missing teeth and an atrophic posterior maxilla who may require augmentation of the maxillary sinus prior to or at placement of dental implants.

\section{Types of interventions}

Any bone augmentation technique, active agent (such as bone morphogenetic proteins, platelet-rich plasma) or biomaterials used together with osseointegrated, root-formed dental implants. For trials to be considered in this review, implants have to be placed and the success/failure of the implant therapy has to be reported at least at the endpoint of the abutment connection procedure. The following time points were considered: abutment connection, prosthetic loading, up to 1 year, 3 and 5 years after loading.

\section{Types of outcome measures}

Outcome measures included.

- Prosthesis failure: planned prosthesis which could not be placed due to implant failure(s) and loss of the prosthesis secondary to implant failure(s).

- Implant failure: implant mobility and removal of stable implants dictated by progressive marginal bone loss or infection (biological failures). Biological failures were grouped as early (failure to establish osseointegration) and late failures (failure to maintain the established osseointegration). Failures that occurred before prosthesis placement were considered early failures.

Implant mobility could be assessed manually or with instruments such as Periotest (Siemens AG, Benshein, Germany) or resonance frequency (Osstell, Integration Diagnostics, Göteborg, Sweden).

- Augmentation procedure failure: failure of the augmentation procedure not affecting the success of the implant.

- Major complications at treated sites (e.g. sinusitis, infection, haemorrhage, etc.).

- Major complications at bone donor sites (e.g. nerve injury, gait disturbance, infection, etc.).

- Patient satisfaction.

- Patient preference (only in split-mouth trials).

- Bone gain expressed in mm or percentage.

- Duration of the treatment time starting from the first intervention to the functional loading of the implants.

- Treatment costs.

Trials evaluating only histological outcomes were not considered in this review.

\section{Search methods for identification of studies}

For the identification of studies included or considered for this review, detailed search strategies were developed for each database searched. These were based on the search strategy developed for MEDLINE (OVID) but revised appropriately for each database.
The search strategy used a combination of controlled vocabulary and free text terms and was run with the Cochrane Highly Sensitive Search Strategy (CHSSS) for identifying randomised trials (RCTs) in MEDLINE: sensitivity maximising version (2009 revision) as referenced in Chapter 6.4.11.1 and detailed in box 6.4.c of the Cochrane Handbook for Systematic Reviews of Interventions Version 5.0.2 (updated September 2009) (Higgins 2009). Details of the MEDLINE search are provided in Appendix 1.

\section{Searched databases}

- The Cochrane Oral Health Group's Trials Register (to 7th January 2010), seeAppendix 2.

- The Cochrane Central Register of Controlled Trials

(CENTRAL) (The Cochrane Library 2009, Issue 4), seeAppendix 3.

- MEDLINE via OVID (1950 to 7th January 2010), seeAppendix 1.

- EMBASE via OVID (1980 to 7th January 2010), seeAppendix 4.

The most recent electronic search was undertaken on 7th January 2010 .

\section{Language}

There were no language restrictions.

\section{Unpublished studies}

We wrote to all the authors of the identified RCTs, we checked the bibliographies of all identified RCTs and relevant review articles, and we used personal contacts in an attempt to identify unpublished or ongoing RCTs. In the first version of this review we also wrote to more than 55 oral implant manufacturers and we requested information on trials through an Internet discussion group (implantology@yahoogroups.com), however we discontinued this due to poor yield.

\section{Handsearching}

Details of the journals being handsearched by the Cochrane Oral Health Group's ongoing programme are given on the website: http://www.ohg.cochrane.org/.

The following journals have been identified as being potentially important to be handsearched for this review: British Journal of Oral and Maxillofacial Surgery, Clinical Implant Dentistry and Related Research, Clinical Oral Implants Research, European Journal of Oral Implantology, Implant Dentistry, International Journal of Oral and Maxillofacial Implants, International Journal of Oral and Maxillofacial Surgery, International Journal of Periodontics and Restorative Dentistry, International Journal of Prosthodontics, Journal of Clinical Periodontology, Journal of Dental Research, Journal of Oral Implantology, Journal of Oral and Maxillofacial Surgery, Journal 
of Periodontology, and Journal of Prosthetic Dentistry. Where these have not already been searched as part of the Cochrane Journal Handsearching Programme, the journals were handsearched by one review author up to the month in which the last electronic search was undertaken.

\section{Data collection and analysis}

\section{Study selection}

The titles and abstracts (when available) of all reports identified through the electronic searches were scanned independently by two review authors. For studies appearing to meet the inclusion criteria, or for which there were insufficient data in the title and abstract to make a clear decision, the full report was obtained. The full reports obtained from all the electronic and other methods of searching were assessed independently by two review authors to establish whether the studies met the inclusion criteria or not. Disagreements were resolved by discussion. Where resolution was not possible, a third review author was consulted. All studies meeting the inclusion criteria then underwent validity assessment and data extraction. Studies rejected at this or subsequent stages were recorded in the table of excluded studies, and reasons for exclusion recorded.

\section{Data extraction}

Data were extracted independently by two review authors using specially designed data extraction forms. The data extraction forms were piloted on several papers and modified as required before use. Any disagreement was discussed and a third review author consulted where necessary. All authors were contacted for clarification or missing information. Data were excluded until further clarification was available if agreement could not be reached.

For each trial the following data were recorded.

- Year of publication, country of origin and source of study funding.

- Details of the participants including demographic characteristics, source of recruitment and criteria for inclusion.

- Details of the type of intervention.

- Details of the outcomes reported, including method of assessment, and time intervals.

\section{Risk of bias in included studies}

An assessment of the risk of bias in included studies was undertaken following the recommendations as described in Chapter 8 of the Cochrane Handbook for Systematic Reviews of Interventions 5.0.2 (Higgins 2009). Two review authors independently and in duplicate assessed the risk of bias of all included studies. In the case that the paper to be assessed had one or more review authors in the authors list, it was independently evaluated only by those review authors not involved in the trials. Any disagreement was discussed and where necessary a third review author was consulted to achieve consensus. Authors were contacted directly for clarification.

A specific tool for assessing risk of bias in each included study was adopted. This comprised a description and a judgement for each entry in a risk of bias table, where each entry addressed a specific feature of the study:

- Adequate sequence generation

- Allocation concealment

- Blinding (of outcome assessor)

- Incomplete outcome data addressed

- Free of selective reporting

- Free of other bias.

The judgement for each entry involved answering a question, with answers 'Yes' indicating low risk of bias, 'No' indicating high risk of bias, and 'Unclear' indicating either lack of information or uncertainty over the potential for bias.

After taking into account the additional information provided by the authors of the trials, the overall risk of bias in included studies was assessed using three key domains: allocation concealment, blinding of outcome assessor (where applicable) and completeness of follow-up. Studies were graded into the following categories.

- Low risk of bias (plausible bias unlikely to seriously alter the results) if all three key domains were met.

- High risk of bias (plausible bias that seriously weakens confidence in the results) if one or more key domains were not met.

Further quality assessment was carried out to assess sample size calculations, definition of exclusion/inclusion criteria, and comparability of control and test groups at entry. The quality assessment criteria were pilot tested using several articles.

\section{Measure of treatment effect}

For dichotomous outcomes, the estimate of effect of an intervention was expressed as odds ratios (OR) together with $95 \%$ confidence intervals (CIs). For continuous outcomes, mean differences and standard deviations were used to summarise the data for each group using mean differences and 95\% CIs. Appropriate data were extracted from the split-mouth studies (Lesaffre 2009) and the generic inverse variance method was used to enter these into Review Manager (RevMan).

\section{Unit of analysis issues}

In parallel group studies the statistical unit was the patient and not the augmentation procedure or the implants. In split-mouth studies the augmentation procedures or the prostheses within each pair were the unit of analysis (Lesaffre 2009). 


\section{Dealing with missing data}

All authors were contacted to retrieve missing data from authors of trials. Methods for estimating missing standard deviations in section 7.7.3 of the Cochrane Handbook for Systematic Reviews of Interventions (Higgins 2009) were used.

\section{Assessment of heterogeneity}

The significance of any variations in the estimates of the treatment effects from the different trials was to be assessed by means of Cochran's test for heterogeneity and heterogeneity would have been considered significant if $\mathrm{P}<0.1$. The $\mathrm{I}^{2}$ statistic, which describes the percentage total variation across studies that is due to heterogeneity rather than chance, will be used to quantify heterogeneity with $\mathrm{I}^{2}$ over $50 \%$ being considered moderate to high heterogeneity.

\section{Assessment of reporting biases}

If there had been sufficient numbers of trials (more than 10) in any meta-analysis, publication bias would have been assessed according to the recommendations on testing for funnel plot asymmetry (Egger 1997) as described in the Cochrane Handbook for Systematic Reviews of Interventions (Higgins 2009). If asymmetry were identified we would have examined possible causes.

\section{Data synthesis}

Meta-analysis was undertaken on where were studies of similar comparisons reporting the same outcome measures. Odds ratios were combined for dichotomous data, and mean differences for continuous data, using random-effects models provided there were more than three studies in the meta-analysis. Data from splitmouth studies were to be combined with data from parallel group trials by the method outlined by Elbourne (Elbourne 2002), using the generic inverse variance method in RevMan.

\section{Subgroup analysis and investigation of heterogeneity}

Clinical heterogeneity was to be assessed by examining the types of participants and interventions for all outcomes in each study. It was decided not to formulate any hypotheses to be investigated for subgroup analyses since no significant meta-analysis was expected. However, this may be done in future updates of this review.

\section{Sensitivity analyses}

It was planned to undertake sensitivity analyses to examine the effect of the study quality assessment on the overall estimates of effect. In addition, the effect of including unpublished literature on the review's findings was also to be examined. There were too few trials to undertake these analyses.

\section{R E S U L T S}

\section{Description of studies}

See: Characteristics of included studies; Characteristics of excluded studies.

\section{Characteristics of the trial setting and investigators}

- Of the 29 potentially eligible trials (Froum 1998; Wannfors 2000; Tawil 2001; Hallman 2002; Barone 2005; Boyne 2005; Kassolis 2005; Raghoebar 2005; Steigmann 2005; Szabó 2005; Froum 2006; Suba 2006; Consolo 2007; Mangano 2007; Aimetti 2008; Barone 2008; Cordaro 2008; Froum 2008; Hallman 2008; Schaaf 2008; Bettega 2009; Cannizzaro 2009; Choi 2009; Crespi 2009; Felice 2009a; Felice 2009b; Kim 2009; Torres 2009; Triplett 2009), 19 had to be excluded for various reasons such as: reported only histological outcomes without presenting any implant related outcomes (Barone 2005; Kassolis 2005; Steigmann 2005; Froum 2006; Suba 2006; Consolo 2007; Aimetti 2008; Cordaro 2008; Froum 2008; Hallman 2008; Choi 2009; Crespi 2009; Kim 2009); problems with study design and data reporting (Froum 1998; Tawil 2001; Boyne 2005; Triplett 2009); too short follow-up (Barone 2008); presented data for only 4 out of 16 treated patients (Aimetti 2008); and it was not a randomised controlled trial (RCT) (Mangano 2007).

- Of the 10 included trials, three were conducted in Italy (Cannizzaro 2009; Felice 2009a; Felice 2009b), two in Sweden (Wannfors 2000; Hallman 2002), one in Spain (Torres 2009), one in Germany (Schaaf 2008), one in France (Bettega 2009), one in The Netherlands (Raghoebar 2005), and one was a multicentre trial conducted in four European centres (Belgium, Hungary, UK and Italy) (Szabó 2005).

- Two trials had a parallel group study design (Wannfors 2000; Cannizzaro 2009), six a split-mouth design (Hallman 2002; Raghoebar 2005; Szabó 2005; Bettega 2009; Felice 2009a; Felice 2009b), and two a mixed split-mouth/parallel group design (Schaaf 2008; Torres 2009) but only data from their splitmouth portion could be used in the present review.

- For six trials it was declared that support was received from industry directly involved in the product being tested also in the form of free material (Wannfors 2000; Hallman 2002; Raghoebar 2005; Szabó 2005; Felice 2009a; Felice 2009b) but for one study (Felice 2009b) the discounted implants were not under evaluation. The authors of four trials declared that no support was received from commercial parties whose products were being tested in the trials (Schaaf 2008; Bettega 2009; Cannizzaro 2009; Torres 2009).

- Seven trials were conducted at university or specialist dental clinics and three trials in private practices (Cannizzaro 2009; Felice 2009a; Torres 2009). One of the centres (Bruges, Belgium) of the multicentre trial (Szabó 2005) was also a private practice. 


\section{Characteristics of the interventions}

The following interventions were tested.

\section{Is sinus lift necessary? (one trial with I 5 patients)}

- One to three $5 \mathrm{~mm}$ long implants of $6 \mathrm{~mm}$ in diameter versus one to three $10 \mathrm{~mm}$ or longer implants of $4 \mathrm{~mm}$ in diameter placed in sinuses augmented with $100 \%$ bovine anorganic bone (Bio-Oss, Geistlich Pharmaceutical, Wolhusen, Switzerland) with their lateral windows sealed with a resorbable collagen membrane (OsseoGuard, Biomet 3i, Palm Beach, FL, USA) 4 months prior to loading (Felice 2009a). All augmentation procedures were performed under local anaesthesia. All implants were left to heal submerged for 4 months. Rescue implants (MegaGen Implant Co. Lld., Gyeongbuk, South Korea) as short implants and EZ Plus (MegaGen) as long implants, with internal connection, were used. Implant site preparation was also different since a $5 \mathrm{~mm}$ diameter trephine was used initially to prepare the osteotomy sites for Rescue implants. Provisional screw-retained reinforced resin prostheses were replaced after 4 months by definitive screwretained metal-ceramic prostheses.

\section{Which is the most effective sinus lift procedure? (nine trials with 235 patients)}

- One-stage lateral sinus lift with monocortical iliac bone blocks fixed usually with two implants left to heal for 6 months versus two-stage lateral sinus lift with particulate bone from the iliac crest left to heal for 6 months and then usually two implants were inserted into the healed graft and left to heal for an additional 6 months (Wannfors 2000). All the augmentation procedures were performed under general anaesthesia. All implants were turned titanium self tapping (Nobel Biocare, Göteborg, Sweden) and were rehabilitated with screw-retained cross-arch implant-supported prostheses.

- Two-stage lateral sinus lift with autogenous particulate bone from the mandibular ramus versus two-stage lateral sinus lift with a mixture of $80 \%$ of Bio-Oss and $20 \%$ of particulate bone from the mandibular ramus, left to heal for 6 months in a splitmouth trial (Hallman 2002). A fibrin glue (Tisseel Duo Quick, Immuno, Wien, Austria) was added to the grafts after thrombin (Thrombin, Immuno) for both interventions. A third treatment group was composed of patients who refused to provide autogenous bone but accepted the treatment with a two-stage sinus lift with $100 \%$ Bio-Oss. For the latter group a resorbable porcine-derived collagen barrier (Bio-Gide, Geistlich Pharmaceutical) was used to cover the defect of sinus and the healing time was prolonged to an average of 8.5 months (range: 8 to 9.5). Procedures were performed under local anaesthesia and oral sedation. All implants were turned titanium self tapping (Nobel Biocare, Göteborg, Sweden): Mark II implant type was used in the former two groups and Mark III in the latter. All patients were rehabilitated with screw-retained metal-ceramic fixed prostheses.

- Two-stage lateral sinus lift with autogenous particulate bone from the iliac crest versus two-stage sinus lift with 1.5 to $2 \mathrm{~g}$ beta-tricalcium phosphate (Cerasorb, Curasan AG, Kleinostheim, Germany) left to heal for 6 months (Szabó 2005). In 10 of the 20 patients the alveolar crest was also widened with cortical bone blocks fixed with microscrews. No membranes were used to cover the bone. All the augmentation procedures were performed under general anaesthesia. Patients were instructed not to wear their upper dentures for 30 days. In 16 patients Ankylos (Degussa, Friadent, Germany) implants were used, whereas in four patients Protetim (Hungary) implants were used. The authors did not provide any explanation for using two different implant systems. Two implants were placed in each augmented sinus.

- One-stage sinus lift using one to three $8 \mathrm{~mm}$ long implants placed in simultaneously crestally augmented sinus with autogenous particulate bone, harvested from the implant site, versus one to three $10 \mathrm{~mm}$ or longer implants placed in simultaneously augmented sinuses using the lateral approach with a mixture of $50 \%$ particulate autogenous bone from the tuberosity area and 50\% Bio-Oss (Cannizzaro 2009). A modified 'Cosci technique' was used to crestally augment the sinus. In brief implant sites were prepared with a $2.5 \mathrm{~mm}$ trephine drill up to about $1 \mathrm{~mm}$ of the sinus cortical wall, to collect autogenous bone, and with a $3.1 \mathrm{~mm}$ diameter atraumatic lifting drill. Resorbable barriers (Biomend Extend, Sulzer Dental Inc., Carlsbad, CA, USA) were used to seal the lateral windows. All augmentation procedures were performed under local anaesthesia. All implants were left to heal submerged for 45 days and were functionally loaded within 1 week after abutment connection. All implants were tapered Screw-Vent MP-1 HA Dual Transition Selective Surface implants (Zimmer Dental, Carlsbad, CA, USA) inserted in underprepared osteotomy sites with a torque of at least $35 \mathrm{~N} / \mathrm{cm}$.

- Two-stage sinus lift with lateral window approach using either a synthetic resorbable barrier (Inion, GTR Biodegradable Membrane System, Tampere, Finland) to keep the sinus membrane or $100 \%$ granular Bio-Oss (Felice 2009b). Inion barriers were used to seal the lateral windows. Inion barriers are made of a synthetic co-polymer (trimethylene carbonate 1-lactide polyglycolide) that needs to be softened in a plasticising solution, allowing the membrane to be cut and mould to fit exactly the space. The barrier then hardens in the new position maintaining the new shape and the space. This material should biodegrade in situ after 8-12 weeks. All augmentation procedures were performed under local anaesthesia. After 6 months, one to three implants were placed per side and submerged for 4 months. All implants were Way (Geass, Pozzuolo del Friuli (UD), Italy) with 
a laser treated surface and internal connection. Provisional screwretained reinforced resin prostheses were replaced after 4 months by definitive screw-retained metal-ceramic prostheses.

\section{Trials evaluating the efficacy of platelet-rich plasma (PRP) with grafts (four trials with 114 patients)}

- Two-stage lateral sinus lift with autogenous blocks and particulate bone together with buccal onlays monocorticocancellous bone grafts, to reconstruct the width of the maxilla, fixed with titanium screws harvested from the iliac crest with or without PRP left to heal for 3 months in a split-mouth trial (Raghoebar 2005). Barriers were not used. PRP was made using the Platelet Concentration Collection System kit (PCCS kit, 3i Implant Innovations Inc. Palm Beach Gardens, FL, USA). $54 \mathrm{ml}$ of blood were mixed with $6 \mathrm{ml}$ of anticoagulant (citrate dextrose) and processed with the platelet concentration system. To promote the release of growth factors from the platelets, $10 \%$ calcium chloride solution and the patient's serum, as a source of autologous thrombin, were added before actual reconstruction of the defect with the bone graft. The resulting gel was mixed with the bone graft and some gel was applied at the closure of the wound at the side treated with PRP. Three implants were inserted into the healed graft of each side and were left to heal for additional 6 months. All the augmentation procedures were performed under general anaesthesia. Surgical templates were used to optimise implant insertion. All implants were turned titanium self tapping (Nobel Biocare) and were rehabilitated with two implant-supported prostheses.

- Two-stage sinus lift with lateral window approach using either autogenous particulate bone from the iliac crest alone or the same graft plus PRP (Schaaf 2008). All sites were also horizontally augmented with corticospongeous blocks from the iliac crest fixed with screws. PRP was produced at the university Institutes of Clinical Immunology and Transfusion Medicine under transfusion medical standards. Autologous platelet concentrate from PRP derived from $450 \mathrm{ml}$ CPD-anticoagulated blood. The PRP was concentrated using differential centrifugation, then stored for $24 \mathrm{~h}$ and adjusted up to $10^{10}$ platelets $/ \mathrm{ml}$. The concentrations obtained were 11 to 12 times above the baseline level of whole blood. All augmentation procedures were performed under general anaesthesia. After 4 months of healing, different implant systems (no details provided) were inserted and left to heal submerged for 6 months.

- Two-stage lateral sinus lift with autogenous corticocancellous blocks from the iliac crest versus granules of bone with platelet concentrates (APCs) and a biologic glue (Tissucol, Baxter SA, Maurepas, France), left to heal for 6 months in a split-mouth trial (Bettega 2009). Plateletpheresis was made at least 3 days before surgery on a plateletpheresis collection system (Trima Accel, Version 5.1, Gambro BCT, Lakewood, CO), a single-needle continuous-flow separation system. It was aimed to obtain a post-donation platelet count of more than $100 \times 106$ per ml. Citrate (ACD-A) was used for anticoagulation. APCs were delivered by the cell-processing laboratory in a $20 \mathrm{ml}$ transfer bag that was centrifuged for 15 minutes. The plasma was removed with a plasma extraction device to reach the target volume of 8 to $15 \mathrm{ml}$. $2 \mathrm{ml}$ of cancellous bone was mixed with half of the APCs volume and $1 \mathrm{ml}$ of Tissucol. The remaining APCs were mixed with $0.5 \mathrm{ml}$ Tissucol to obtain a membrane for covering the grafted area. Sites treated with bone blocks were covered by $1 \mathrm{ml}$ of Tissucol. Implants were placed 6 months after the augmentation procedure.

- One trial compared one or two-stage sinus lift procedures using a lateral window technique and $100 \%$ granular Bio-Oss with or without PRP, left to heal for 6 months with a hybrid of split-mouth parallel design trial (Torres 2009). Patients having up to $4 \mathrm{~mm}$ of residual bone height were augmented first and implant were placed after 6 months whereas patients with residual bone more than $4 \mathrm{~mm}$ up to $7 \mathrm{~mm}$ received implants during the sinus lift procedures. Implants were left to heal unloaded for 6 months. 10 to $20 \mathrm{cc}$ of venous blood were collected 30 minutes prior to the surgery and mixed with a $3.8 \%$ sodium citrate solution at a 5/1 ratio, achieving anticoagulation through calcium binding. The blood was then centrifuged into three and separated into three layers: red blood cells (RBCs), PRP and poor plasma. Flow cytometry was used for platelet counting. Platelets counts were $2.97 \pm 0.7$-fold over peripheral blood. PRP was activated with $30 \% \overline{\mathrm{CaCl}_{2}}$ solution and a PRP gel was obtained and mixed with Bio-Oss. The entire bone of the buccal window was removed, and, after the sinus was filled with the bone substitute no barrier was used to seal the window. Patients were instructed not to wear their upper dentures for 2 to 3 weeks after surgery. Osseotite (Biomet 3I, Palm Beach, FL, USA) implants were used.

\section{Characteristics of outcome measures}

- Prosthesis failure: Wannfors 2000; Hallman 2002; Raghoebar 2005; Szabó 2005; Cannizzaro 2009; Felice 2009a; Felice 2009b; Torres 2009.

- Implant failure by individual implant stability assessment with removed prostheses (with the exception for single implants): Wannfors 2000; Hallman 2002; Raghoebar 2005; Szabó 2005; Schaaf 2008; Bettega 2009; Cannizzaro 2009; Felice 2009a; Felice 2009b; Torres 2009.

- Augmentation procedure failure: Wannfors 2000; Hallman 2002; Raghoebar 2005; Szabó 2005; Schaaf 2008; Bettega 2009; Cannizzaro 2009; Felice 2009a; Felice 2009b; Torres 2009.

- Major complications at treated sites: perforation of the sinus membrane only (though not a major complication): Wannfors 2000; various complications: Hallman 2002; Raghoebar 2005; Szabó 2005; Schaaf 2008; Bettega 2009; Cannizzaro 2009; Felice 2009a; Felice 2009b; Torres 2009. 
- Major complications at bone donor site: Hallman 2002; Raghoebar 2005; Szabó 2005; Cannizzaro 2009. In our analyses, complications at treated and donor sites were combined when appropriate.

- Patient satisfaction: no trial.

- Patient preference (only in split-mouth trials): Felice 2009a; Felice 2009b. Data for one trial (Felice 2009a) were reported, however they might be biased because of the study design. All augmentation procedures were performed first and, after 4 months, test and control implants were placed bilaterally in the same surgical session. The potential advantage of having the prostheses on the short implants loaded 4 months earlier was lost with this study design.

- Bone gain expressed in mm or percentage: vertical bone gain was measured in $\mathrm{mm}$ by direct measurement in three trials (Schaaf 2008; Bettega 2009; Felice 2009b), however for two trials (Schaaf 2008; Bettega 2009) data were presented in a way we could not use.

- Duration of the treatment period starting from the first intervention to the functional loading of the implants: all trials.

- Treatment costs: no trials. However, this outcome measure was indirectly extrapolated by us for all trials.

\section{Duration of follow-up (including unpublished data kindly provided by the investigators)}

- To the abutment connection (Szabó 2005; Schaaf 2008; Bettega 2009).

- Four-month post-loading (Felice 2009a; Felice 2009b).

- One-year post-loading (Hallman 2002; Cannizzaro 2009).

- Two-year post-loading (Raghoebar 2005; Torres 2009).

- Three-year post-loading (Wannfors 2000).

\section{Risk of bias in included studies}

The final quality scoring after having incorporated the additional information kindly provided by the authors of the trials is summarized in Additional Table 1. For each trial we assessed whether it was at low or high risk of bias. Six studies were judged to be at high risk of bias, and four at low risk of bias.

\section{Allocation concealment}

When assessing the information presented in the articles, allocation concealment was scored adequate for four trials (Cannizzaro 2009; Felice 2009a; Felice 2009b; Torres 2009) and unclear for all others. When evaluating authors' replies one trial was judged to be properly concealed (Hallman 2002), one trial was judged not to be properly concealed (Schaaf 2008) and four trials remained unclear (Wannfors 2000; Raghoebar 2005; Szabó 2005; Bettega 2009).

\section{Blinding}

Blinding was not feasible in all of the included studies. Based on evaluation of the trial reports, outcome assessment was scored as blinded for three trials (Raghoebar 2005; Cannizzaro 2009; Felice 2009b), not possible for one trial (Felice 2009a), though an independent assessor was used, and unclear for the remaining six trials. When evaluating authors' replies, the outcome assessors of two trials were judged to be blinded (Schaaf 2008; Torres 2009) and not blinded for three trials (Wannfors 2000; Hallman 2002; Szabó 2005). Blinding of outcome assessment for non-radiological outcomes in Bettega 2009 is unclear.

\section{Completeness of follow-up}

When assessing the information presented in the articles, information on drop outs was clearly presented in all trials with one exception (Torres 2009) but the author supplied the missing information.

\section{Inclusion/exclusion criteria}

For more details see the Characteristics of included studies table.

\section{Main inclusion criteria}

- Severely resorbed maxillae (classes V-VI according to Cawood 1991) with maxillary sinuses having $<5 \mathrm{~mm}$ in height of residual alveolar bone with reduced stability and retention of upper dentures (Raghoebar 2005).

- 1 to $5 \mathrm{~mm}$ in height of residual alveolar bone in the floor of the edentulous sinus (Felice 2009b).

- 2 to $7 \mathrm{~mm}$ in height of residual alveolar bone in the floor of the edentulous sinus (Wannfors 2000).

- 3 to $6 \mathrm{~mm}$ in height of residual alveolar bone in the floor of the edentulous sinus (Cannizzaro 2009).

- 4 to $6 \mathrm{~mm}$ in height of residual alveolar bone in the floor of the edentulous sinus (Felice 2009a).

- Less than $5 \mathrm{~mm}$ in height of residual alveolar bone in the floor of the edentulous sinus (Hallman 2002; Szabó 2005).

- Less than $8 \mathrm{~mm}$ in height of residual alveolar bone in the floor of the edentulous sinus (Bettega 2009).

- Severe atrophy of the edentulous or partially edentulous posterior maxilla, and intention to treat with onlay bone blocks and sinus floor augmentation (Schaaf 2008). Residual bone height values appear to be in the range of 1 to $12 \mathrm{~mm}$ according to the measurements kindly provided by the authors.

- 1 to $7 \mathrm{~mm}$ in height of residual alveolar bone in the floor of the edentulous sinus (Torres 2009).

\section{Main exclusion criteria}

- Smokers (Bettega 2009).

- Bone metabolic diseases (Wannfors 2000). 
- Medication interfering with bone metabolism (i.e. corticosteroids, bisphosphonate, etc.) (Wannfors 2000;

Cannizzaro 2009; Felice 2009a; Felice 2009b).

- Sinusitis (Wannfors 2000; Bettega 2009; Cannizzaro 2009;

Felice 2009a; Felice 2009b).

- History of maxillary sinusitis or sinus surgery (Bettega

2009; Torres 2009).

- History of reconstructive, pre-prosthetic surgery or previous oral implantology (Raghoebar 2005).

- Edentulous period less than 1 year (Raghoebar 2005).

- Severe systemic disease (ASA III and IV) (Torres 2009).

- None specified (Hallman 2002; Szabó 2005).

\section{Sample size}

A priori calculation for the sample size was reported in only two trials (Cannizzaro 2009; Felice 2009a); however in one trial (Cannizzaro 2009) the number of included patients did not reach the calculated sample size.

\section{Baseline comparability between treatment groups}

- No apparent major baseline differences (Wannfors 2000; Raghoebar 2005; Felice 2009b; Torres 2009).

- Unclear whether major baseline differences existed (Hallman 2002; Szabó 2005; Schaaf 2008; Bettega 2009).

- The following major baseline differences existed: more large diameter implants were placed in the sites treated with $8 \mathrm{~mm}$ long implants and crestal sinus lift (Cannizzaro 2009), and short $6 \mathrm{~mm}$ diameter implants were compared to longer implants with a $4 \mathrm{~mm}$ diameter (Felice 2009a).

\section{Effects of interventions}

See: Summary of findings for the main comparison

\section{Is sinus lift necessary? (one trial with I 5 patients)}

- One trial compared implants $5 \mathrm{~mm}$ long with $6 \mathrm{~mm}$ diameter versus different implants at least $10 \mathrm{~mm}$ long with a diameter of $4 \mathrm{~mm}$, placed in laterally augmented sinus with $100 \%$ Bio-Oss (Felice 2009a). Only patients having 4 to $6 \mathrm{~mm}$ of residual alveolar bone height with a thickness of $8 \mathrm{~mm}$ or more below the sinus were included. Fifteen patients were treated according to a split-mouth design. All patients were followed up to 4 months after loading, therefore there were no drop outs. One prosthesis could not be placed when planned in the short implant side because one implant was found to be mobile at abutment connection. This is not statistically significant ( $\mathrm{McNemar} \mathrm{P}=1.00$, exact odds ratio (Stata 'epitab' procedure) is 0 (95\% confidence interval (CI) 0 to 39); unable to calculate standard error (SE) to display data in RevMan). The implant was successfully replaced by an implant placed more distally and loaded. Four perforations of the sinus lining occurred: one in the augmented group versus three in the $5 \mathrm{~mm}$ long implant group. The difference was not statistically significant, McNemar $\mathrm{P}=$ 0.50 , exact odds ratio (Stata) is 0 (95\% CI 0 to 5.3) (unable to calculate SE to display data in RevMan). All patients expressed no preference for any of the two procedures, judging both of them as acceptable however this measurement was considered to be biased as previously described in the 'Characteristics of outcome measures'. With respect to cost and treatment time, the long implant group required one additional surgical intervention for placing the implants (two-stage procedure) plus the cost of the bone substitute with the barrier and 4 additional months to complete the treatment. This trial was judged to be at low risk of bias.

\section{Which is the most effective sinus lift procedure? (nine trials with 235 patients)}

- One trial compared two techniques for augmenting atrophic maxillary sinuses (Wannfors 2000) (Analysis 1.1). Only patients having 2 to $7 \mathrm{~mm}$ of residual alveolar bone in the floor of the edentulous sinus were included. Twenty patients were treated with a one-stage sinus lift with monocortical iliac bone blocks, and other 20 patients were treated with a two-stage sinus lift with particulate bone from the iliac crest. All patients were followed up to 3 years after loading; there were no drop outs. However, data were presented in a way which could not be used for all the time points we wanted to evaluate. Three patients refused to have their prostheses removed and $\mathrm{x}$-ray examination at the 3-year follow-up. The only complications reported were 11 perforations of the sinus membrane in nine patients of the one-stage group versus 11 perforations in 10 patients of the twostage group. At the time of abutment connection 11 implants in eight patients were found to be not osseointegrated in the onestage group versus seven implants in six patients of the two-stage group. At 1 year an additional five implants were lost in the onestage group versus one in the two-stage group. At 3 years one additional implant was lost in the one-stage group versus two in the two-stage group. Two patients of the one-stage group had problems with the fixed prostheses at 1 year. In one patient the prosthesis was lost due to four implant failures whereas in another patient the prosthesis had to be redesigned due to lack of space for the tongue (we did not consider this as a prosthesis failure in the calculations, since it was independent of the bone grafting technique). One prosthesis was lost due to the failure of a strategically positioned implant at 1 year in the two-stage group. There was no statistically significant difference between the two treatment groups for any of the outcomes considered in this review. With respect to cost and treatment time, all the procedures were performed under general anaesthesia, however the two-stage group required one additional surgical intervention for placing the implants whereas implants were placed concurrently with the augmentation procedure in the one-stage 
group. The healing period was 6 months longer in the two-stage group. This trial was judged to be at high risk of bias.

- One trial compared three two-stage techniques for augmenting atrophic maxillary sinuses (Hallman 2002) (Analysis 1.2). Only patients with less than $5 \mathrm{~mm}$ of alveolar bone height in the sinus floor and fixed dentition on the opposite jaw were included. The trial was designed as a sort of split-mouth/parallel preference trial. Eleven patients willing to provide autogenous bone from the mandibular ramus were treated with a splitmouth approach (autogenous bone versus 80\% Bio-Oss and $20 \%$ autogenous bone), whereas 10 patients who refused to have their bone harvested from the mandible were treated with $100 \%$ Bio-Oss. All patients were followed up to 1 year after loading; there were no drop outs. During the post-operative phase no complications occurred in either the augmented sites or the donor sites. However a severe resorption of the autogenous bone graft occurred in two patients. At abutment connection six implants failed in five patients in the group treated with autogenous bone only and two implants failed in two patients in the group treated with $80 \%$ Bio-Oss. No implants or prostheses were lost at the 1-year evaluation. The author informed us that additional implants were lost at the 2-year follow-up in two patients, causing the failure of the fixed prostheses. The complete information should be published in a future 5-year follow-up report. There was no statistically significant difference for any of the outcomes considered in this review. With respect to cost and treatment time, the only difference in cost was the use of the bone substitute. The healing period was 6 months. The trial was judged to be at high risk of bias.

- One trial compared two techniques for augmenting atrophic maxillary sinuses (Szabó 2005) (Analysis 1.3). Only patients with less than $5 \mathrm{~mm}$ of alveolar bone height in the sinus floor were included. Twenty patients were treated with a splitmouth approach with a two-stage sinus lift with particulate bone from the iliac crest one side and with a two-stage sinus lift with $100 \%$ Cerasorb (a beta-tricalcium phosphate bone substitute) on the contralateral sinus. In 10 patients an additional autogenous onlay bone block was placed to widen the alveolar crest. All patients were followed up to implant loading and there were no drop outs. No serious post-operative complications occurred at the implant sites. Three complications occurred at the bone graft donor sites: one permanent sensory loss of the lateral femoral cutaneous nerve and two had prolonged wound drainage (2 to 3 weeks). At abutment connection two implants failed, one in each group, they both had to be replaced in order to place the prosthesis and this caused a delay of 3 to 6 months (we did not consider these as prosthesis failures in the calculations). There was no statistically significant difference between the two treatments for any of the outcomes considered in this review. With respect to cost and treatment time, the only difference was the cost of the bone substitute. The trial was judged to be at high risk of bias.

- One trial compared two one-stage techniques for augmenting maxillary sinuses (Cannizzaro 2009) (Analysis 1.4). Only patients having 3 to $6 \mathrm{~mm}$ bone height at the sinus floor were included. Twenty patients were treated with a sinus lift through a crestal approach and autogenous bone and $8 \mathrm{~mm}$ long implants, and 20 patients were treated with a sinus lift through a lateral window approach with a mixture of $50 \%$ particulate autogenous bone from the tuberosity area and 50\% Bio-Oss and implants at least $10 \mathrm{~mm}$ long. All patients were followed up to 1 year after loading, and there were no drop outs. Four complications occurred in four sinuses laterally augmented - one abscess and one sinusitis, both determining the failure of the graft and the implants, versus one peri-implant infection in the short implant group. One implant failed in the short implant group at abutment connection and five implants (four in the immediate post-operative phase and one at abutment connection) in three patients in the long implant group. Two prostheses could not be placed in the long implant group versus one in the short implant group because of implant failures. There was no statistically significant difference for any of the outcomes considered in this review. There was an additional cost of the bone substitute in the group with the lateral approach. All implants were loaded 7 weeks after sinus lift. The trial was judged to be at low risk of bias.

- One trial compared two two-stage techniques for augmenting maxillary sinuses using a lateral window approach (Felice 2009b) (Analysis 1.5; Analysis 1.6). Only patients having 1 to $5 \mathrm{~mm}$ bilateral bone height at the sinus floor were included. Ten patients were treated with a split-mouth approach. After elevation of the sinus lining, one side was filled with granular Bio-Oss whereas in the contra-lateral site, an Inion resorbable rigid barrier was used to maintain space to allow bone regeneration. All patients were followed up to 4 months after loading, and there were no drop outs. After 6 months, both interventions gained a statistically significant amount of bone (14.4 mm for Inion versus $14.1 \mathrm{~mm}$ for Bio-Oss) but there was no statistically significant difference between the procedures. There were no differences in complications between groups (two perforations of the maxillary lining at the Inion treated sites versus one at Bio-Oss site, Analysis 1.5), however, in one of the patients where a perforation occurred at the Inion site, at implant placement, the sinus was two thirds filled with soft tissue. Implants were placed anyway and the site was successfully retreated with Bio-Oss. No implant failed. The clinician preferred Bio-Oss because it was simpler to handle. There were no statistically significant differences in patient preference for either of the two techniques 1 month after surgery and 1 month after delivery of definitive prostheses: eight patients had no preference while two preferred the Bio-Oss treated side. With respect to cost, both procedures used Inion barriers, but only one 
procedure used the Bio-Oss. There was no difference in time taken to complete the augmentation procedure (19.8 minutes for Inion versus 20.5 for Bio-Oss) and all implants were loaded 11 months after sinus lift. The trial was judged to be at low risk of bias.

\section{Trials evaluating the efficacy of platelet-rich plasma (PRP) with grafts (four trials with 1 I 4 patients)}

- One trial compared two techniques for augmenting resorbed maxillae including atrophic maxillary sinuses (Raghoebar 2005) (Analysis 1.7). Only patients with less than 5 $\mathrm{mm}$ of alveolar bone height in the sinus floor were included. Five patients were treated with a split-mouth approach with two-stage sinus lift with autogenous bone together with buccal onlay grafts, harvested from the iliac crest, one side with PRP and the other without. All patients were followed for 2 years after implant loading and there were no drop outs. No serious complications occurred at the grafted sites: one sinus membrane was perforated during surgery but healing was uneventful. A small incision breakdown occurred in the first week at the non-PRP side of one patient. A seroma which healed uneventfully was the only complication that occurred at the donor sites. During the prosthetic phase one implant failed in the PRP side, but no prosthesis failed. There was no statistically significant difference between the two techniques for any of the outcomes considered in this review. The difference in cost and treatment time was the use of PRP. Prostheses were inserted about 10 months after augmentation. The trial was judged to be at high risk of bias.

- One trial compared two-stage sinus lift with lateral window approach using either autogenous particulate bone from the iliac crest alone or the same graft with PRP in fully edentulous patients (Schaaf 2008) (Analysis 1.7). All sites were also horizontally augmented with corticospongeous blocks and left to heal for 4 months. There were two publications for this trial. The first publication included 34 patients treated according to a split-mouth design and 19 patients treated according to parallel group design but no clinical data were provided. In the second publication only the clinical data of the 34 patients treated with a split-mouth approach were presented and only these data are presented in this review. All patients were followed up to abutment connection (6 months after implant insertion) and there were no drop outs. Only complications at augmented sites were reported: one sinusitis in two patients, one from each group. Six patients experienced implant failures at abutment connection: one patient lost one implant at both sites, three patients lost one implant each at the non-PRP treated sites only, and two patients lost one and three implants at the PRP side. There was no statistically significant difference between the two techniques for any of the outcomes considered in this review. The difference in cost and treatment time was the use of PRP. The trial was judged to be at high risk of bias.
- One trial compared two two-stage techniques for augmenting maxillary sinuses (Bettega 2009) (data not shown). Only patients with less than $8 \mathrm{~mm}$ of alveolar bone height in the sinus floor were included. Eighteen patients were treated with a split-mouth approach with two-stage sinus lift with autogenous bone blocks from the iliac crest and Tissucol on one side and autologous granular bone and autologous platelet concentrate (APC) with Tissucol on the other. Patients were followed for 1 year after implant placement and there were two drop outs before implant placement for financial reasons. There was no complication due to cytapheresis or surgery. All implants were stable 1 year after placement. There was no statistically significant difference between the two techniques for any of the outcomes considered in this review. The difference in cost and treatment time was the use of APCs. The trial was judged to be at high risk of bias.

- One trial compared one or two-stage sinus lift procedures using a lateral window technique and $100 \%$ granular Bio-Oss with or without PRP, left to heal for 6 months with a hybrid of split-mouth/parallel design trial (Torres 2009). In the original publication there were 87 patients included but only the data from the 57 patients treated according to a split-mouth procedure are presented here (Analysis 1.7). Twenty-five patients having up to $4 \mathrm{~mm}$ of residual bone height were augmented first and 98 implants were placed after 6 months whereas in 32 patients with residual bone ranging between $4 \mathrm{~mm}$ to $7 \mathrm{~mm} 128$ implants were placed simultaneously to the sinus augmentation procedure. Implants were left to heal unloaded for 6 months. All patients were followed for 2 years after loading and there were no drop outs. Five perforations of the maxillary membrane occurred in five patients: three patients belonged to the PRP group and two to the non-PRP group. Partial loss of the graft occurred in five patients treated with the two-stage procedure: two patients belonged to the PRP group and three to the non-PRP group. According to the authors no prosthesis failed. Four implants failed in three patients treated according a two-stage procedure. Three implants failed in two patients at sides which were not treated with PRP. There was no statistically significant difference between the group receiving PRP and the group that did not receive PRP for any of the outcomes considered in this review. The difference in cost and treatment time was the use of PRP. The trial was judged to be at low risk of bias.

Meta-analysis was only possible for the three trials which compared, in split-mouth trials, particulate bone from the iliac crest (Raghoebar 2005; Schaaf 2008) or Bio-Oss (Torres 2009) with and without PRP. In two studies (Raghoebar 2005; Schaaf 2008), sites were also augmented with onlay blocks of autogenous bone. There were no statistically significant differences between groups who received PRP and those who did not for implant failures and complications (Figure 1).

Interventions for replacing missing teeth: augmentation procedures of the maxillary sinus (Review) 
Figure I. Forest plot of comparison: I Different sinus lift procedures, outcome: I.7 Autogenous bone or Bio-Oss +/- PRP.

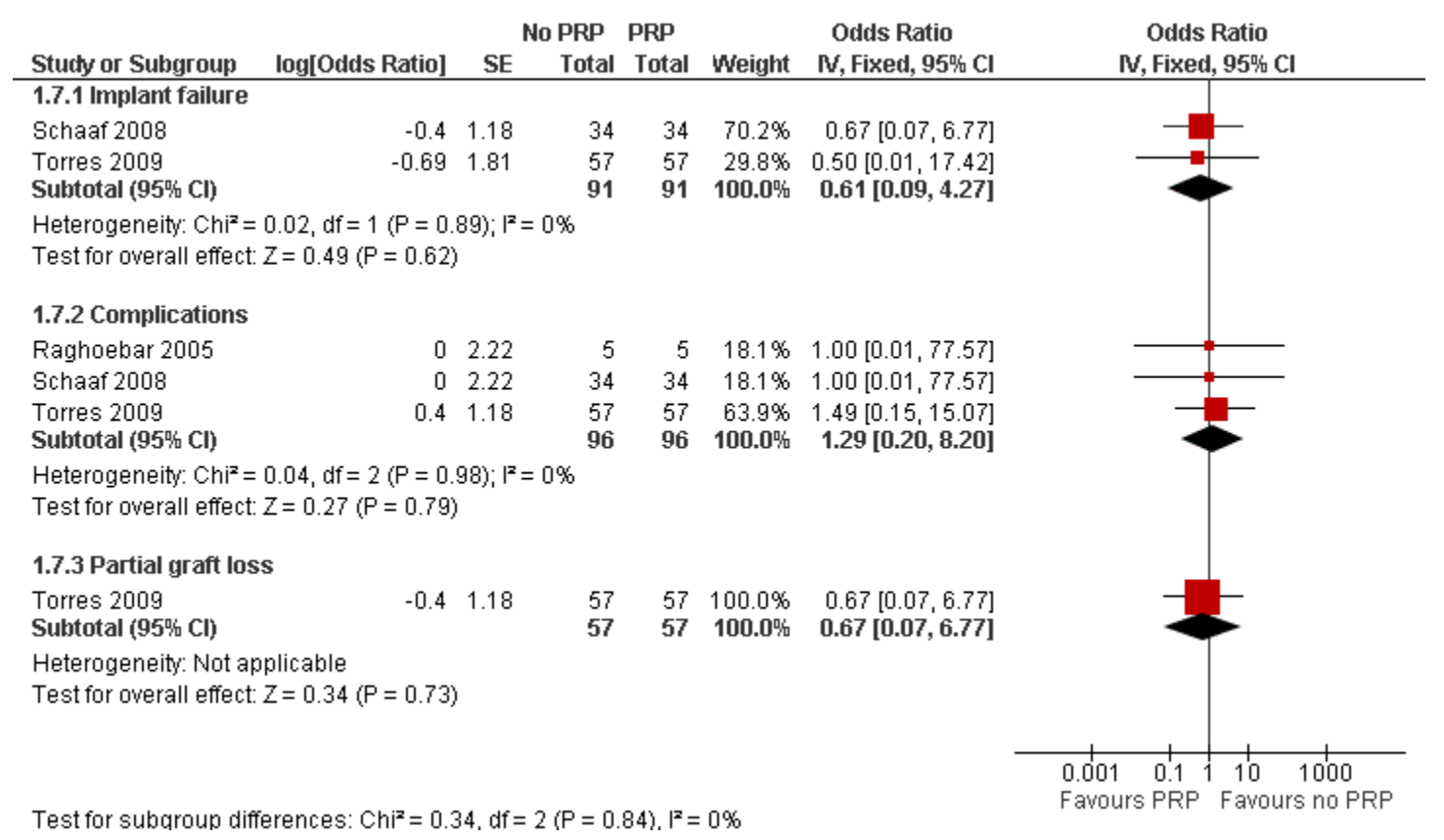

\section{DISCUSSION}

Twenty-nine potentially eligible trials were identified, but only 10 met our inclusion criteria. Twelve trials had to be excluded because presented only histological data. The observation that the majority of randomised clinical trials evaluating sinus lift procedures report only histological findings without providing any useful information on the actual clinical outcome of the sinus lift procedure and implant rehabilitation, is both disappointing and alarming. This is not to say that histological information is not useful, but if not backed up by meaningful clinical outcomes it appears that human beings are used instead of animal as histological experimental models and this is difficult to justify.

Sample sizes were relatively small with only two trials (Cannizzaro 2009; Felice 2009a) reporting a sample size calculation. It is therefore possible that many of these trials were underpowered to demonstrate any significant difference between groups. Nevertheless the included trials did provide limited but indeed useful insight into possible avenues for future clinical research and some clinical indications which should be carefully evaluated by clinicians when deciding whether to perform an augmentation procedure or not, or which augmentation procedure to select.
We first evaluated whether and when it may be necessary to augment maxillary sinus and then which are the most effective augmentation procedures. This distinction is relevant since it is possible that ineffective procedures which could be even potentially dangerous are widely performed, despite no improvements of treatment prognosis or patients' quality of life.

Only one trial evaluated whether sinus lift procedures are indicated in patients having a residual crestal height between 4 to $6 \mathrm{~mm}$ ( Felice 2009a). The findings of this study are inconclusive due to the small sample size and the short follow-up (4 months after loading), however, they suggest that $5 \mathrm{~mm}$ long implants with a diameter of $6 \mathrm{~mm}$ can be successfully loaded 4 months after placement without the need of any augmentation procedure. Though the only implant failure occurred in the short implant group, the implant was successfully replaced with another short implant placed more distally. There is the need for more trials to understand in which clinical situations sinus lift procedures are beneficial for patients.

When evaluating which are the most effective augmentation procedures we have eight trials providing some indications (Wannfors 2000; Hallman 2002; Raghoebar 2005; Szabó 2005; Schaaf 2008; Bettega 2009; Cannizzaro 2009; Felice 2009b). Studies can be grouped in the following way.

When trying to answer the question whether grafting is necessary to obtain bone regeneration, even in case of severely atrophic sinus, 
the findings from the only pilot trial investigating this hypothesis (Felice 2009b) clearly indicated that a graft is not needed to obtain new bone in the sinus cavity, if it is possible to keep sufficient space using a resorbable rigid barrier. On the other hand, the operator found that it was technically simpler to use a bone substitute rather than to mould a space-maintaining barrier. The same study also suggested that there is not a clear correlation between the amount of newly formed bone, evaluated with histomorphometry, and the clinical success of the implants. In fact, all implants became successfully osseointegrated also in presence of an average of $24 \%$ of newly formed bone. In general, using surrogate outcomes, such as histomorphometry, as the only outcome on which to predict implant success in case of sinus augmentations with various materials, is shown to be inaccurate and misleading. Clinically relevant primary outcomes such as implant failure and complication rates should be used in conjunction with surrogate outcomes.

The question whether autogenous bone could be replaced by bone substitutes to reduce patient morbidity was addressed in two trials (Hallman 2002; Szabó 2005). One trial (Szabó 2005) is of little use because the follow-up was limited to abutment connection and onlay bone blocks were used in half of the patients. The findings of other trial (Hallman 2002) suggest that $80 \%$ to $100 \%$ of Bio-Oss can be used as bone substitute. Autogenous bone grafting might be replaced by bone substitutes for this indication, however larger trials with longer follow-up should be conducted to validate these preliminary findings.

One trial compared a one-stage crestal sinus lift procedure with autogenous bone and $8 \mathrm{~mm}$ long implants with a lateral window sinus lift with a mix of autogenous bone and $50 \%$ Bio-Oss to place longer implants (Cannizzaro 2009). Though no statistically significant differences were found, there were more complications and failures with the lateral window augmentation procedure. It is interesting to observe that all implants were placed in bone with a residual height of 3 to $6 \mathrm{~mm}$ and were loaded less than 2 months after sinus lift. It is generally accepted that 2 months in humans is insufficient time to allow for new bone formation. Therefore the original bone must have been sufficient to hold the implants, with both lifting procedures adding little or no benefit.

When comparing a one-stage monocortical bone block versus a two-stage technique with particulate bone harvested from the iliac crest for maxillary sinus lifting, no statistically or clinically significant differences were observed (Wannfors 2000). However, the use of autogenous bone blocks from the iliac crest in a one-stage procedure is a technique seldom used nowadays and most of the sinus lifting procedures are now performed under local anaesthesia.

Four trials (Raghoebar 2005; Schaaf 2008; Bettega 2009; Torres 2009) evaluated the possible advantage of using platelet-rich plasma (PRP) to speed bone healing for sinus augmentation. There is no evidence of a clinical benefit from the use of PRP, therefore there appears to be no reasons to justify its use in this application.

Most of the augmentation procedures evaluated in these trials were performed by experienced clinicians, therefore caution is recommended when extrapolating the results of the present review to other clinical settings, such as general practice. Clinicians should carefully evaluate the potential added benefits for each individual patient of maxillary sinus augmentation. Where a benefit is anticipated the more effective procedure associated with fewer risks of complication/discomfort for the patient should be selected.

\section{AUTHORS, CONCLUSIONS Implications for practice}

Conclusions are based on 10 small trials including 250 patients, sometimes with short follow-up, and generally assessed as being at high risk of bias. Therefore these results should be interpreted with great caution and should be viewed as very preliminary, requiring confirmation by large multicentre trials.

- One trial investigated whether and when it is necessary to augment maxillary sinus.

(1) It is still unclear when sinus lift procedures are needed.

(2) Implants $5 \mathrm{~mm}$ long and $6 \mathrm{~mm}$ wide can be successfully loaded in maxillary bone with a residual height of 4 to $6 \mathrm{~mm}$ below the sinus without making any augmentation procedure, though the long-term prognosis is unclear.

- Nine trials investigated which are the most effective sinus lift techniques, four of which evaluated the efficacy of plateletrich plasma (PRP).

(1) If the residual alveolar bone height is 3 to $6 \mathrm{~mm}$, a crestal approach to lift the sinus lining and place $8 \mathrm{~mm}$ implants may possibly lead to fewer complications than a lateral window approach to place implants at least $10 \mathrm{~mm}$ long.

(2) Keeping the sinus lining elevated by means of a rigid resorbable barrier in presence of 1 to $5 \mathrm{~mm}$ of residual bone height without the addition of a graft is sufficient to regenerate new bone to allow rehabilitation with implant-supported prostheses. However, it is technically simpler to fill the sinus with a granular bone substitute.

(3) Bone substitutes such Bio-Oss and Cerasorb appear to be as effective as autogenous bone grafts for augmenting atrophic maxillary sinuses, therefore they could be used as a replacement for autogenous bone grafting.

(4) There is no evidence that the addition of PRP treatment to autogenous bone grafts or bone substitutes improves the outcome of sinus lift procedures for implant rehabilitation. 


\section{Implications for research}

In order to understand when sinus lift procedures are needed and which are the most effective sinus lift techniques, larger, well designed trials are needed. Such trials should include long-term follow-up and be reported according to the Consolidated Standards of Reporting Trials (CONSORT) guidelines (Moher 2001) (http:/ /www.consort-statement.org/). It is difficult to provide clear indications with respect of which sinus lift procedures should be evaluated first, however, once established in which clinical situations these procedures are actually needed, priority should be given to those interventions that are simpler, less invasive, involve less risk of complications, and reach their goals within the shortest timeframe. Research efforts should be concentrated on a few important clinical questions, using larger sample sizes. This might be obtained through collaborative efforts among various research groups. Among of the identified research priorities is to evaluate whether and when one-stage lifting via a crestal approach can replace the more invasive lateral window procedures and whether bone substitutes can be used for replacing autogenous bone in augmenting severely atrophic maxillary sinuses.

\section{ACKNOWLEDGEMENTS}

We wish to thank all those people who helped us with the final preparation of the current review, and in particular: Anne Littlewood (Cochrane Oral Health Group) and Sylvia Bickley for their assistance with literature searching; Luisa Fernandez Mauleffinch and Philip Riley (Cochrane Oral Health Group) for their help with the preparation of this review; Stella Kwan as a coauthor of one previous version of this review; Lars Andersson, Filippo Cangini, Mats Hallman, Björn Johansson, Adriano Piattelli, Gerry Raghoebar, Heidrun Schaaf, Andreas Thor and Jesus Torres for kindly providing us with additional information on their trials. We would also like to thank the following referees: Stephen Chen, Matteo Chiapasco, Christer Dahlin, Mats Hallman, Jayne Harrison, Jan Hirsch, Anne Littlewood, Ian Needleman, Michele Nieri, Gerry Raghoebar, Heidrun Schaaf, Bill Shaw and Jesus Torres.

\section{R E F E R E N C E S}

\section{References to studies included in this review}

Bettega 2009 \{published data only\}

* Bettega G, Brun JP, Boutonnat J, Cracowski JL, Quesada JL, Hegelhofer $\mathrm{H}$, et al.Autologous platelet concentrates for bone graft enhancement in sinus lift procedure. Transfusion 2009;49:779-85.

Bettega G, Brun JP, Cracowski JL, Vérain A, Raphael B. [Use of autologous platelet concentrates during pre-implantation maxillary reconstruction]. Revue de Stomatologie et de Chirurgie Maxillofaciale 2005;106(3):189-91.

Cannizzaro 2009 \{published data only\} Cannizzaro G, Felice P, Leone M, Viola P, Esposito M. Early loading of hydroxyapatite coated implants in the atrophic posterior maxilla: lateral sinus lift with autogenous bone and Bio-Oss versus crestal mini-sinus lift and $8 \mathrm{~mm}$ implants. A randomized controlled clinical trial. European Journal of Oral Implantology 2009;2:25-38.

Felice 2009a \{published data only\}

Felice P, Checchi V, Pistilli R, Scarano A, Pellegrino G, Esposito $\mathrm{M}$. Bone augmentation versus $5 \mathrm{~mm}$ long dental implants in posterior atrophic jaws. Four-month postloading results from a randomized controlled clinical trial. European Journal of Oral Implantology 2009;2:267-81.

Felice 2009b \{published data only\}

Felice P, Esposito M, Scarano A, Pistilli R, Lizio G, Checchi L. A comparison of two techniques to augment maxillary sinus with the lateral approach: no grafting procedure vs anorganic bone placement. Preliminary histological and clinical outcomes of a randomized controlled clinical trial. Clinical Oral Implants Research 2009;20:973 (Abs 261).

* Felice P, Scarano A, Pistilli R, Checchi L, Piattelli $\mathrm{M}$, Pellegrino $\mathrm{G}$, et al.A comparison of two techniques to augment maxillary sinuses using the lateral window approach: rigid synthetic resorbable barriers versus anorganic bovine bone. Five-month post-loading clinical and histological results of a pilot randomized controlled clinical trial. European Journal of Oral Implantology 2009;2: 293-306.

Hallman 2002 \{published and unpublished data\} Hallman M, Sennerby L, Lundgren S. A clinical and histologic evaluation of implant integration in the posterior maxilla after sinus floor augmentation with autogenous bone, bovine hydroxyapatite, or a 20:80 mixture. The International Journal of Oral and Maxillofacial Implants 2002;17(5):635-43.

Raghoebar 2005 \{published and unpublished data\} Raghoebar GM, Schortinghuis J, Liem RS, Ruben JL, van der Wal JE, Vissink A. Does platelet-rich plasma promote remodeling of autologous bone grafts used for augmentation of the maxillary sinus floor?. Clinical Oral Implants Research 2005;16(3):349-56.

Schaaf 2008 \{published and unpublished data\}

Schaaf H, Streckbein P, Lendeckel S, Heidinger K, Görtz B, Bein $G$, et al.Topical use of platelet-rich plasma to influence bone volume in maxillary augmentation: a prospective randomized trial. Vox Sanguinis 2008;94(1):64-9.

* Schaaf H, Streckbein P, Lendeckel S, Heidinger K, Rehmann P, Boedeker RH, et al.Sinus lift augmentation using autogenous bone grafts and platelet-rich plasma: 
radiographic results. Oral Surgery, Oral Medicine, Oral Pathologhy, Oral Radiology and Endodontics 2008;106: 673-8.

Szabó 2005 \{published and unpublished data\}

Szabó G, Huys L, Coulthard P, Maiorana C, Garagiola $\mathrm{U}$, Barabas J, et al.A prospective multicenter randomized clinical trial of autogenous bone versus beta-tricalcium phosphate graft alone for bilateral sinus elevation: histologic and histomorphometric evaluation. The International Journal of Oral and Maxillofacial Implants 2005;20(3): 371-81.

Torres 2009 \{published data only\}

Torres J, Tamimi F, Martinez PP, Alkhraisat MH, Linares R, Hernandez G, et al.Effect of platelet-rich plasma on sinus lifting: a randomized-controlled clinical trial. Journal of Periodontology 2009;36:677-87.

Wannfors 2000 \{published and unpublished data\} Johansson B. Bone Grafts and Dental Implants in the Reconstruction of the Severely Atrophied, Edentulous Maxilla. Uppsala: Uppsala University, 2001.

Johansson B. Bone grafts. In manuscript 2005.

* Wannfors K, Johansson B, Hallman M, Strandkvist T. A prospective randomized study of 1- and 2-stage sinus inlay bone grafts: 1-year follow-up. The International Journal of Oral and Maxillofacial Implants 2000;15(5):625-32.

\section{References to studies excluded from this review}

Aimetti 2008 \{published and unpublished data\}

Aimetti M, Romano F, Dellavia C, De Paoli S. Sinus grafting using autogenous bone and platelet-rich plasma: histologic outcomes in humans. The International Journal of Periodontics and Restorative Dentistry 2008;28:585-91.

Barone 2005 \{published data only\} Barone A, Crespi R, Nicoli N, Fini M, Giardino R, Covani U. Maxillary sinus augmentation: histologic and histomorphometric analysis. The International Journal of Oral and Maxillofacial Implants 2005;20:519-25.

Barone 2008 \{published data only\}

Barone A, Santini S, Marconcini S, Giacomelli L, Gherlone E, Covani U. Osteotomy and membrane elevation during the maxillary sinus augmentation procedure. A comparative study: piezoelectric device vs conventional rotative instruments. Clinical Oral Implants Research 2008;19: $511-5$.

Boyne 2005 \{published data only\} Boyne PJ, Lilly LC, Marx RE, Moy PK, Nevins M, Spagnoli $\mathrm{DB}$, et al.De novo bone induction by recombinant human bone morphogenetic protein-2 (rh BMP-2) in maxillary sinus floor augmentation. Journal of Oral and Maxillofacial Surgery 2005;63(12):1693-707.

Choi 2009 \{published data only\}

Choi KS, Kan JY, Boyne PJ, Goodacre CJ, Lozada JL, Rungcharassaeng $\mathrm{K}$. The effects of resorbable membrane on human maxillary sinus graft: a pilot study. The International Journal of Oral and Maxillofacial Implants 2009;24:73-80.
Consolo 2007 \{published data only\}

Consolo U, Zaffe D, Bertoldi C, Ceccherelli G. Plateletrich plasma activity on maxillary sinus floor augmentation by autologous bone. Clinical Oral Implants Research 2007; 18(2):252-62.

Cordaro 2008 \{published data only\} Cordaro L, Bosshardt DD, Palattella P, Rao W, Serino G, Chiapasco M. Maxillary sinus grafting with Bio-Oss or Straumann Bone Ceramic: histomorphometric results from a randomized controlled multicenter clinical trial. Clinical Oral Implants Research 2008;19:796-803.

Crespi 2009 \{published data only\}

Crespi R, Mariani E, Benasciutti E, Capparé P, Cenci S, Gherlone E. Magnesium-enriched hydroxyapatite versus autologous bone in maxillary sinus grafting: combining histomorphometry with osteoblast gene expression profiles ex vivo. Journal of Periodontology 2009;80:586-93.

Froum 1998 \{published data only\}

* Froum SJ, Tarnow DP, Wallace SS, Rohrer MD, Cho $\mathrm{S}$-C. Sinus floor elevation using anorganic bovine bone matrix (OsteoGraf/N) with and without autogenous bone: a clinical, histologic, radiographic, and histomorphometric analysis - Part 2 of an ongoing prospective study. The International Journal of Periodontics and Restorative Dentistry 1998;18(6):529-43.

Tarnow DP, Wallace SS, Froum SJ, Rohrer MD, Cho SC. Histologic and clinical comparison of bilateral sinus floor elevations with and without barrier membrane placement in 12 patients: Part 3 of an ongoing prospective study. The International Journal of Periodontics and Restorative Dentistry 2000;20(2):117-25.

Froum 2006 \{published data only\} Froum SJ, Wallace SS, Elian N, Cho SC, Tarnow DP. Comparison of mineralized cancellous bone allograft (Puros) and anorganic bovine bone matrix (Bio-Oss) for sinus augmentation: histomorphometry at 26 to 32 weeks after grafting. The International Journal of Periodontics and Restorative Dentistry 2006;26(6):543-51.

Froum 2008 \{published data only\}

Froum SJ, Wallace SS, Cho SC, Elian N, Tarnow DP. Histomorphometric comparison of a biphasic bone ceramic to anorganic bovine bone for sinus augmentation: 6 - to 8 month postsurgical assessment of vital bone formation. A pilot study. The International Journal of Periodontics and Restorative Dentistry 2008;28:273-81.

Hallman 2008 \{published data only\} Hallman M, Lindgren C, Sennerby L, Mordenfeld A, Strandkvist T. Clinical histology of SLA microimplants placed into different biomaterials. EAO conference, Warsaw. 2008.

Kassolis 2005 \{published data only\} Kassolis JD, Reynolds MA. Evaluation of the adjunctive benefits of platelet-rich plasma in subantral sinus augmentation. The Journal of Craniofacial Surgery 2005;16 (2):280-7. 
Kim 2009 \{published data only\}

Kim YK, Yun PY, Kim SG, Lim SC. Analysis of the healing process in sinus bone grafting using various grafting materials. Oral Surgery, Oral Medicine, Oral Pathology, Oral Radiology, and Endodontics 2009;107:204-11.

Mangano 2007 \{published and unpublished data\} Mangano C, Scarano A, Perrotti V, Iezzi G, Piattelli A. Maxillary sinus augmentation with a porous synthetic hydroxyapatite and bovine-derived hydroxyapatite: a comparative clinical and histologic study. The International Journal of Oral and Maxillofacial Implants 2007;22(6): 980-6.

Steigmann 2005 \{published data only\}

Steigmann M, Garg AK. A comparative study of bilateral sinus lifts performed with platelet-rich plasma alone versus alloplastic graft material reconstituted with blood. Implant Dentistry 2005;14(3):261-6.

Suba 2006 \{published data only\}

Suba Z, Takács D, Matusovicz D, Fazekas A, Szabó G, Barabás J. Quantitative and qualitative comparison of the maxillary bone regeneration after beta-tricalcium phosphate and autogenous bone implantation $[\mathrm{A}$ maxilla csontregeneraciojanak mennyisegi es minosegi osszehasonlitasa beta-tricalcium phosphate es autolog csontbeultetes utan]. Fogorvosi Szemle 2006;99(1):21-8. * Suba Z, Takács D, Matusovits D, Barabás J, Fazekas A, Szabó G. Maxillary sinus floor grafting with beta-tricalcium phosphate in humans: density and microarchitecture of the newly formed bone. Clinical Oral Implants Research 2006; 17(1):102-8.

Tawil 2001 \{published data only\}

Tawil G, Mawla M. Sinus floor elevation using a bovine bone mineral (Bio-Oss) with or without the concomitant use of a bilayered collagen barrier (Bio-Guide): a clinical report of immediate and delayed implant placement. The International Journal of Oral and Maxillofacial Implants 2001;16(5):713-21.

Triplett 2009 \{published data only\}

Triplett RG, Nevins M, Marx RE, Spagnoli DB, Oates TW, Moy PK, et al.Pivotal, randomized, parallel evaluation of recombinant human bone morphogenetic protein-2/ absorbable collagen sponge and autogenous bone graft for maxillary sinus floor augmentation. Journal of Oral and Maxillofacial Surgery 2009;67:1947-60.

\section{Additional references}

Aghaloo 2007

Aghaloo TL, Moy PK. Which hard tissue augmentation techniques are the most successful in furnishing bony support for implant placement?. The International Journal of Oral and Maxillofacial Implants 2007;22(Suppl):49-70.

Aparicio 2001

Aparicio C, Perales P, Rangert B. Tilted implants as an alternative to maxillary sinus grafting: a clinical, radiologic, and periotest study. Clinical Implant Dentistry and Related Research 2001;3:39-49.

\section{Boyne 1980}

Boyne PJ, James RA. Grafting of the maxillary sinus floor with autogenous marrow and bone. Journal of Oral Surgery 1980;38:613-6.

\section{Brånemark 1977}

Brånemark PI, Hansson BO, Adell R, Breine U, Lindstrom $\mathrm{J}$, Hallen $\mathrm{O}$, et al.Osseointegrated implants in the treatment of the edentulous jaw. Experience from a 10-year period. Scandinavian Journal of Plastic and Reconstructive Surgery. Supplementum 1977;16:1-132.

\section{Brånemark 2004}

Brånemark PI, Gröndahl K, Öhrnell LO, Nilsson, P, Petruson B, Svensson B, et al.Zygoma fixture in the management of advanced atrophy of the maxilla: technique and long-term results. Scandinavian Journal of Plastic and Reconstructive Surgery 2004;38(2):70-85.

\section{Cannizzaro 2007}

Cannizzaro G, Leone M, Consolo U, Ferri V, Licitra $\mathrm{G}$, Worthington $\mathrm{H}$, et al.Augmentation of the posterior atrophic edentulous maxilla with implants placed in the ulna: a prospective single-blind controlled clinical trial. The International Journal of Oral and Maxillofacial Implants 2007;22:280-8.

\section{Cawood 1991}

Cawood JI, Howell RA. Reconstructive preprosthetic surgery. I. Anatomical considerations. International Journal of Oral and Maxillofacial Surgery 1991;20(2):75-82.

\section{Cosci 2000}

Cosci F, Luccioli M. A new sinus lift technique in conjunction with placement of 265 implants: a 6-year retrospective study. Implant Dentistry 2000;9:363-8.

\section{das Neves 2006}

das Neves FD, Fones D, Bernardes SR, do Prado CJ, Neto AJ. Short implants - an analysis of longitudinal studies. The International Journal of Oral and Maxillofacial Implants 2006;21:86-93.

\section{Del Fabbro 2004}

Del Fabbro M, Testori T, Francetti L, Weinstein R. Systematic review of survival rates for implants placed in the grafted maxillary sinus. The International Journal of Periodontics and Restorative Dentistry 2004;24(6):565-77.

\section{Egger 1997}

Egger M, Smith GD, Schneider M, Minder C. Bias in meta-analysis detected by a simple, graphical test. $B M J$ 1997;315:629-34.

Elbourne 2002

Elbourne DR, Altman DG, Higgins JP, Curtin F, Worthington HV, Vail A. Meta-analyses involving crossover trials: methodological issues. International Journal of Epidemiology 2002;31(1):140-9.

\section{Emmerich 2005}

Emmerich D, Att W, Stappert C. Sinus floor elevation using osteotomes: a systematic review and meta-analysis. Journal of Periodontology 2005;76(8):1237-51. 
Esposito 2005

Esposito M, Worthington HV, Coulthard P. Interventions for replacing missing teeth: dental implants in zygomatic bone for the rehabilitation of the severely deficient edentulous maxilla. Cochrane Database of Systematic Reviews 2005, Issue 4. [Art. No.: CD004151. DOI: 10.1002/ 14651858.CD004151.pub2]

\section{Esposito 2007}

Esposito M, Murray-Curtis L, Grusovin MG, Coulthard P, Worthington HV. Interventions for replacing missing teeth: different types of dental implants. Cochrane Database of Systematic Reviews 2007, Issue 4. [DOI: 10.1002/ 14651858.CD003815.pub3]

Esposito 2009

Esposito M, Grusovin MG, Felice P, Karatzopoulos G, Worthington HV, Coulthard P. Interventions for replacing missing teeth: horizontal and vertical bone augmentation techniques for dental implant treatment. Cochrane Database of Systematic Reviews 2009, Issue 4. [DOI: 10.1002/ 14651858.CD003607.pub4]

Gabbert 2009

Gabbert O, Koob A, Schmitter M, Rammelsberg P. Implants placed in combination with an internal sinus lift without graft material: an analysis of short-term failure. Journal of Clinical Periodontology 2009;36:177-83.

\section{Graves 1994}

Graves SL. The pterygoid plate implant: a solution for restoring the posterior maxilla. The International Journal of Periodontics and Restorative Dentistry 1994;14:513-23.

\section{Hatano 2007}

Hatano N, Sennerby L, Lundgren S. Maxillary sinus augmentation using sinus membrane elevation and peripheral venous blood for implant-supported rehabilitation of the atrophic posterior maxilla: case series. Clinical Implant Dentistry and Related Research 2007;9: $150-5$.

\section{Higgins 2009}

Higgins JPT, Green S (editors). Cochrane Handbook for Systematic Reviews of Interventions version 5.0.2 (updated September 2009). The Cochrane Collaboration, 2009. Available from www.cochrane-handbook.org.

\section{Lesaffre 2009}

Lesaffre E, Philstrom B, Needleman I, Worthington H. The design and analysis of split-mouth studies: What statisticians and clinicians should know. Statistics in Medicine 2009;28(28):3470-82.

Lundgren 2004

Lundgren S, Andersson S, Gualini F, Sennerby L. Bone reformation with sinus membrane elevation: a new surgical technique for maxillary sinus floor augmentation. Clinical Implant Dentistry and Related Research 2004;6:165-73.

\section{Moher 2001}

Moher D, Schulz KF, Altman DG. The CONSORT statement revised recommendations for improving the quality of reports of parallel-group randomised trials. The Lancet 2001;357(9263):1191-4.

\section{Nedir 2006}

Nedir R, Bischof M, Vazquez L, Szmukler-Moncler S, Bernard J P. Osteotome sinus floor elevation without grafting material: a 1-year prospective pilot study with ITI implants. Clinical Oral Implants Research 2006;17:679-86.

Nkenke 2009

Nkenke E, Stelzle F. Clinical outcomes of sinus floor augmentation for implant placement using autogenous bone or bone substitutes: a systematic review. Clinical Oral implants Research 2009;20(Suppl 4):124-33.

Palmer 2000

Palmer P, Palmer R. Implant surgery to overcome anatomical difficulties. In: Palmer R editor(s). A Clinical Guide to Implants in Dentistry. London: British Dental Association, 2000:57-65.

\section{Pjetursson 2008}

Pjetursson BE, Tan WC, Zwahlen M, Lang NP. A systematic review of the success of sinus floor elevation and survival of implants inserted in combination with sinus floor elevation. Journal of Clinical Periodontology 2008;35(8 Suppl):216-40.

\section{Pjetursson 2009}

Pjetursson BE, Ignjatovic D, Matuliene G, Brägger U, Schmidlin K, Lang NP. Transalveolar maxillary sinus floor elevation using osteotomes with or without grafting material. Part II: Radiographic tissue remodeling. Clinical Oral Implants Research 2009;20:677-83.

\section{Renouard 2006}

Renouard F, Nisand D. Impact of implant length and diameter on survival rates. Clinical Oral Implants Research 2006;17(Suppl 2):35-51.

\section{Sohn 2008}

Sohn DS, Lee JS, Ahn MR, Shin HI. New bone formation in the maxillary sinus without bone grafts. Implant Dentistry 2008;17:321-31.

\section{Summers 1994}

Summers RB. A new concept in maxillary implant surgery: the osteotome technique. Compendium of Continuing Education in Dentistry 1994;15:152-8.

\section{Summers 1995}

Summers RB. The osteotome technique: Part 4 - Future site development. Compendium of Continuing Education in Dentistry 1995;16:1080-92.

\section{Tan 2008}

Tan WC, Lang NP, Zwahlen M, Pjetursson BE. A systematic review of the success of sinus floor elevation and survival of implants inserted in combination with sinus floor elevation. Part II: transalveolar technique. Journal of Clinical Periodontology 2008;35(8 Suppl):241-54.

Tatum 1986

Tatum H. Maxillary and sinus implant reconstructions. Dental Clinics of North America 1986;30(2):207-29.

\section{Thor 2007}

Thor A, Sennerby L, Hirsch JM, Rasmusson L. Bone formation at the maxillary sinus floor following simultaneous elevation of the mucosal lining and implant 
installation without graft material: an evaluation of 20 patients treated with 44 Astra Tech implants. Journal of Oral and Maxillofacial Surgery 2007;65(7 Suppl 1):64-72.

\section{Tong 1998}

Tong DC, Rioux K, Drangsholt M, Beirne OR. A review of survival rates for implants placed in grafted maxillary sinuses using meta-analysis. The International Journal of Oral and Maxillofacial Implants 1998;13(2):175-82.

\section{Urist 1965}

Urist MR. Bone: formation by autoinduction. Science 1965;150(3698):893-9.

\section{Valentin-Opran 2002}

Valentin-Opran A, Wozney J, Csimma C, Lilly L, Riedel GE. Clinical evaluation of recombinant human bone morphogenic protein-2. Clinical Orthopaedics and Related Research 2002;395:110-20.

Wallace 2003

Wallace SS, Froum SJ. Effect of maxillary sinus augmentation on the survival of endosseous dental implants. A systematic review. Annals of Periodontology 2003;8(1): $328-43$.

\section{References to other published versions of this review}

\section{Coulthard 2003}

Coulthard P, Esposito M, Jokstad A, Worthington HV. Interventions for replacing missing teeth: bone augmentation techniques for dental implant treatment. Cochrane Database of Systematic Reviews 2003, Issue 3. [Art. No.: CD003607. DOI: 10.1002/14651858.CD3607]

\section{Esposito 2006a}

Esposito M, Grusovin MG, Worthington HV, Coulthard P. Interventions for replacing missing teeth: bone augmentation techniques for dental implant treatment. Cochrane Database of Systematic Reviews 2006, Issue 1. [Art. No.: CD003607. DOI: 10.1002/ 14651858.CD3607.pub2]

\section{Esposito 2006b}

Esposito M, Grusovin MG, Coulthard P, Worthington HV. The efficacy of various bone augmentation procedures for dental implants: a Cochrane systematic review of randomized controlled clinical trials. The International Journal of Oral and Maxillofacial Implants 2006;21(5): 696-710.

\section{Esposito 2008}

Esposito M, Grusovin MG, Kwan S, Worthington HW, Coulthard P. Interventions for replacing missing teeth: bone augmentation techniques for dental implant treatment. Cochrane Database of Systematic Reviews 2008, Issue 3. [DOI: 10.1002/14651858.CD003607.pub3]

* Indicates the major publication for the study 


\title{
CHARACTERISTICS OF STUDIES
}

\section{Characteristics of included studies [ordered by study ID]}

\author{
Bettega 2009
}

Methods Randomised, split-mouth study, 1-year post-implant placement follow-up. Two withdrawals for financial reasons

Participants

Patients having less than $8 \mathrm{~mm}$ of alveolar bone at the floor of the sinus. Adults treated at the Plastic and Maxillofacial Surgery Unit, Grenoble, France. Exclusion criteria were smokers, maxillary sinus lesion or history of sinusitis or sinus surgery, abnormal blood counts, ASA score 2 or more. 18 patients were treated

Interventions

Two-stage sinus lift with autogenous cortico-cancellous blocks from the iliac crest versus granules of bone with platelet concentrates (APCs) and a biologic glue (Tissucol, Baxter SA, Maurepas, France) left to heal for 6 months in a split-mouth trial. Plateletpheresis was made at least 3 days before surgery on a plateletpheresis collection system (Trima Accel, Version 5.1, Gambro BCT, Lakewood, CO), a single-needle continuous-flow separation system. It was aimed to obtain a post-donation platelet count of more than $100 \times 106$ per ml. Citrate (ACD-A) was used for anticoagulation. APCs were delivered by the cellprocessing laboratory in a $20 \mathrm{ml}$ transfer bag that was centrifuged for 15 minutes. The plasma was removed with a plasma extraction device to reach the target volume of 8 to $15 \mathrm{ml} .2 \mathrm{ml}$ of cancellous bone was mixed with half of the APCs volume and $1 \mathrm{ml}$ of Tissucol. The remaining APCs were mixed with $0.5 \mathrm{ml}$ Tissucol to obtain a membrane for covering the grafted area. Sites treated with the bone block were covered by $1 \mathrm{ml}$ of Tissucol. Implants were placed 6 months after the augmentation procedure

Outcomes

Implant failure. Complications at the augmented and donor sites. Histomorphometrical and radiographic evaluation: sinus floor height and bone density on panoramic radiographs and CT scans

Notes

\section{Risk of bias}

\begin{tabular}{|c|c|c|}
\hline Item & Authors' judgement & Description \\
\hline Adequate sequence generation? & Yes & $\begin{array}{l}\text { Article: "(Randomization) was chosen } \\
\text { through a two-element randomization ta- } \\
\text { ble" }\end{array}$ \\
\hline Allocation concealment? & Unclear & $\begin{array}{l}\text { Article: "The iliac crest graft was then har- } \\
\text { vested, and the destination for the two tech- } \\
\text { niques (traditional versus APC) was chosen } \\
\text { through a two-element randomization ta- } \\
\text { ble" } \\
\text { Author did not reply to our request for clar- } \\
\text { ification. }\end{array}$ \\
\hline
\end{tabular}

Interventions for replacing missing teeth: augmentation procedures of the maxillary sinus (Review) 


\begin{tabular}{|c|c|c|}
\hline $\begin{array}{l}\text { Blinding? } \\
\text { All outcomes }\end{array}$ & Unclear & $\begin{array}{l}\text { Article: "All radiological images were read } \\
\text { blindly by a radiologist". However it was } \\
\text { not specified if the other outcome measures } \\
\text { were assessed blindly } \\
\text { Author did not reply to our request for clar- } \\
\text { ification. }\end{array}$ \\
\hline $\begin{array}{l}\text { Incomplete outcome data addressed? } \\
\text { All outcomes }\end{array}$ & No & $\begin{array}{l}\text { Data partially presented. } \\
\text { Author did not reply to our request for clar- } \\
\text { ification. }\end{array}$ \\
\hline Free of selective reporting? & Yes & $\begin{array}{l}\text { All outcomes reported were previously de- } \\
\text { scribed in the published research protocol }\end{array}$ \\
\hline Free of other bias? & Yes & \\
\hline
\end{tabular}

Cannizzaro 2009

Methods

Participants

Interventions
Randomised trial of parallel group design, 1-year post-loading follow-up. No withdrawals

Patients having 3 to $6 \mathrm{~mm}$ of alveolar bone at the floor of the sinus. Adults treated at a private dental practice, Pavia, Italy. Exclusion criteria were: general contraindications to implant surgery, subjected to irradiation in the head and neck area less than 1 year ago, treated or under treatment with intravenous amino-bisphosphonates, poor oral hygiene and motivation, uncontrolled diabetes, pregnant or lactating, substance abusers, psychiatric problems or unrealistic expectations, lack of opposite occluding dentition/ prosthesis in the area intended for implant placement, acute infection in the area intended for implant placement. 20 patients were treated in each group

One-stage sinus lift using one to three $8 \mathrm{~mm}$ long implants placed in simultaneously crestally augmented sinus with autogenous particulate bone, harvested from the implant site, versus one to three $10 \mathrm{~mm}$ or longer implants placed in simultaneously augmented sinuses using the lateral approach with a mixture of $50 \%$ particulate autogenous bone from the tuberosity area and 50\% Bio-Oss. A modified 'Cosci technique' was used to crestally augment the sinus. In brief implant sites were prepared with a $2.5 \mathrm{~mm}$ trephine drill up to about $1 \mathrm{~mm}$ of the sinus cortical wall, to collect autogenous bone, and with a $3.1 \mathrm{~mm}$ diameter atraumatic lifting drill. Resorbable barriers (Biomend Extend, Sulzer Dental Inc., Carlsbad, CA, USA) were used to seal the lateral windows. All the augmentation procedures were performed under local anaesthesia. All implants were left to heal submerged for 45 days and were functionally loaded within 1 week after abutment connection. All implants were tapered Screw-Vent MP-1 HA Dual Transition Selective Surface implants (Zimmer Dental, Carlsbad, CA, USA) inserted in under prepared osteotomy sites with a torque of at least $35 \mathrm{~N} / \mathrm{cm}$

Outcomes

Prosthesis and implant failure. Complications at the augmented and donor sites. Periimplant marginal bone levels

Notes

Interventions for replacing missing teeth: augmentation procedures of the maxillary sinus (Review) 
Cannizzaro 2009 (Continued)

Risk of bias

\begin{tabular}{|c|c|c|}
\hline Item & Authors' judgement & Description \\
\hline Adequate sequence generation? & Yes & $\begin{array}{l}\text { Article: "A computer generated restricted } \\
\text { randomisation list was created" }\end{array}$ \\
\hline Allocation concealment? & Yes & $\begin{array}{l}\text { Article: "Only one of the investigators } \\
\text { (Marco Esposito), not involved in the se- } \\
\text { lection and treatment of the patients, was } \\
\text { aware of the randomization sequence and } \\
\text { could have access to the randomization list } \\
\text { stored in his pass-word protected portable } \\
\text { computer. The randomized codes were en- } \\
\text { closed in sequentially numbered, identical, } \\
\text { opaque, sealed envelopes. Envelopes were } \\
\text { opened sequentially after eligible patients } \\
\text { were anaesthetised, therefore, treatment al- } \\
\text { location was concealed to the investigators } \\
\text { in charge of enrolling and treating the pa- } \\
\text { tients" }\end{array}$ \\
\hline $\begin{array}{l}\text { Blinding? } \\
\text { All outcomes }\end{array}$ & Yes & $\begin{array}{l}\text { Article: "One dentist (Giuseppe Fontana) } \\
\text { not involved in the treatment of the pa- } \\
\text { tients made all the clinical assessments } \\
\text { without knowing group allocation, there- } \\
\text { fore outcome assessor was blinded, how- } \\
\text { ever Bio-Oss augmented sites could be } \\
\text { identified on radiographs because they ap- } \\
\text { peared more radio-opaque and implants } \\
\text { were longer" }\end{array}$ \\
\hline $\begin{array}{l}\text { Incomplete outcome data addressed? } \\
\text { All outcomes }\end{array}$ & Yes & All data presented, no drop outs. \\
\hline Free of selective reporting? & Yes & All planned outcomes were reported. \\
\hline Free of other bias? & Unclear & $\begin{array}{l}\text { The } 8 \mathrm{~mm} \text { implants were in general of } \\
\text { larger diameter than the longer implants, } \\
\text { therefore it cannot be ruled out that also } \\
\text { the implant diameter played a role in the } \\
\text { clinical outcome }\end{array}$ \\
\hline
\end{tabular}


Methods

Participants
Randomised trial of split-mouth design, 4-month post-loading follow-up. No withdrawals

Patients having 4 to $6 \mathrm{~mm}$ of alveolar bone at the floor of the sinus. Adults treated in dental hospitals/university clinics in Bologna, Roma and Chieti, Italy. Exclusion criteria were: general contraindications to implant surgery, patients irradiated in the head and neck area, immunosuppressed or immunocompromised patients, patients who took or are taking bisphosphonates intravenously, patients with periodontitis, poor oral hygiene and motivation, uncontrolled diabetes, pregnancy or lactation, addiction to alcohol or drugs, psychiatric problems, lack of opposite occluding dentition in the area intended for implant placement, patients with an acute or chronic infection inflammation in the area intended for implant placement. 15 patients were treated

Interventions

One to three $5 \mathrm{~mm}$ long implants of $6 \mathrm{~mm}$ in diameter versus one to three $10 \mathrm{~mm}$ or longer implants of $4 \mathrm{~mm}$ in diameter placed in sinuses augmented with $100 \%$ bovine anorganic bone (Bio-Oss, Geistlich Pharmaceutical, Wolhusen, Switzerland) with their lateral windows sealed with a resorbable collagen membrane (OsseoGuard, Biomet 3i, Palm Beach, FL, USA) 4 months before. All augmentation procedures were performed under local anaesthesia. All implants were left to left to heal submerged for 4 months. Rescue implants (MegaGen Implant Co. Lld., Gyeongbuk, South Korea) as short implants and EZ Plus (MegaGen) as long implants, all with internal connection were used. Implant site preparation was also different since a $5 \mathrm{~mm}$ diameter trephine was used initially to prepare the osteotomy sites for Rescue implants. Provisional screw-retained reinforced resin prostheses were replaced after 4 months by definitive screw-retained metal-ceramic prostheses

Outcomes

Prosthesis and implant failure. Complications at the treated sites. Peri-implant marginal bone levels and patient preference

Notes

Risk of bias

\begin{tabular}{|c|c|c|}
\hline Item & Authors' judgement & Description \\
\hline Adequate sequence generation? & Yes & $\begin{array}{l}\text { Article: "A computer generated restricted } \\
\text { randomisation list was created" }\end{array}$ \\
\hline Allocation concealment? & Yes & $\begin{array}{l}\text { Article: "Only one of the investigators } \\
\text { (ME), not involved in the selection and } \\
\text { treatment of the patients, was aware of the } \\
\text { randomisation sequence and could have } \\
\text { access to the randomisation list stored } \\
\text { in his pass-word protected portable com- } \\
\text { puter. The randomised codes were en- } \\
\text { closed in sequentially numbered, identical, } \\
\text { opaque, sealed envelopes. Envelopes indi- } \\
\text { cating which site to augment were opened } \\
\text { sequentially just prior to the augmentation }\end{array}$ \\
\hline
\end{tabular}


Felice 2009a (Continued)

procedure. Therefore, treatment allocation was concealed to the investigators in charge of enrolling and treating the patients"

Blinding? Yes

All outcomes

(2)

Article: "One dentist (GP) not involved in the treatment of the patients performed all clinical and radiographic assessments without knowing group allocation, therefore the outcome assessor was blinded, however the Bio-Oss augmented sites could be identified both clinical when testing implant stability because of the different diameters and on radiographs because they appeared more radio-opaque and implants were different"

Incomplete outcome data addressed? Yes All outcomes

Free of selective reporting?

Free of other bias?
Yes

No
All data presented, no drop outs.

All planned outcomes were reported.

Implants of small diameter $(4 \mathrm{~mm})$ and of different design were inserted with a different surgical technique in the augmented group instead of the originally planned identical but longer implants

Patients had always the augmentation procedure performed first and then had implant placement bilaterally. This may have affected patient preference since patient could not experience the benefit of having the prosthesis 4 months earlier

Felice 2009b

Methods

Participants
Randomised trial of split-mouth design, 5-month post-loading follow-up. No withdrawals

Patients having 1 to $4 \mathrm{~mm}$ of alveolar bone at the floor of the sinus. Adults treated in dental hospitals/university clinics in Bologna, Roma and Chieti, Italy. Exclusion criteria were: general contraindications to implant surgery, patients irradiated in the head and neck area, immunosuppressed or immunocompromised patients, patients who took or are taking bisphosphonates intravenously, patients with periodontitis, poor oral hygiene and motivation, uncontrolled diabetes, pregnancy or lactation, addiction to alcohol or drugs, psychiatric problems, lack of opposite occluding dentition in the area intended for implant placement, patients with an acute or chronic infection inflammation in the area intended for implant placement. 10 patients were treated 
Felice 2009b (Continued)

\begin{tabular}{|c|c|}
\hline Interventions & $\begin{array}{l}\text { Two-stage sinus lift with lateral window approach using either a synthetic resorbable } \\
\text { barrier (Inion, GTR Biodegradable Membrane System, Tampere, Finland) to keep the } \\
\text { sinus membrane or } 100 \% \text { granular Bio-Oss. Inion barriers were used to seal the lateral } \\
\text { windows. Inion barriers are made of a synthetic co-polymer (trimethylene carbonate 1- } \\
\text { lactide polyglycolide) that needs to be softened in a plasticising solution, allowing the } \\
\text { membrane to be cut and mould to fit exactly the space. The barrier then harden in the new } \\
\text { position maintaining the new shape and the space. This material should biodegrade in situ } \\
\text { after } 8-12 \text { weeks. All augmentation procedures were performed under local anaesthesia. } \\
\text { After } 6 \text { months, one to three implants were placed per side and submerged for } 4 \text { months. } \\
\text { All implants were Way (Geass, Pozzuolo del Friuli (UD), Italy) with a laser treated } \\
\text { surface and internal connection. Provisional screw-retained reinforced resin prostheses } \\
\text { were replaced after } 4 \text { months by definitive screw-retained metal-ceramic prostheses }\end{array}$ \\
\hline
\end{tabular}

Outcomes

Prosthesis and implant failure. Complications at the treated sites. Amount of vertically augmented bone $(\mathrm{mm})$. Peri-implant marginal bone levels, patient and clinician preference. Time necessary to complete the augmentation procedure

Notes

Risk of bias

\begin{tabular}{|c|c|c|}
\hline Item & Authors' judgement & Description \\
\hline Adequate sequence generation? & Yes & $\begin{array}{l}\text { Article: "A computer generated restricted } \\
\text { randomisation list was created" }\end{array}$ \\
\hline Allocation concealment? & Yes & $\begin{array}{l}\text { Article: "Only one of the investigators } \\
\text { (Marco Esposito), not involved in the se- } \\
\text { lection and treatment of the patients, was } \\
\text { aware of the randomization sequence and } \\
\text { could have access to the randomization list } \\
\text { stored in his pass-word protected portable } \\
\text { computer. The randomized codes were en- } \\
\text { closed in sequentially numbered, identical, } \\
\text { opaque, sealed envelopes. Envelopes were } \\
\text { opened sequentially after the sinus lining } \\
\text { epithelium of site number } 1 \text { was lifted, } \\
\text { therefore, treatment allocation was con- } \\
\text { cealed to the investigators in charge of en- } \\
\text { rolling and treating the patients" }\end{array}$ \\
\hline $\begin{array}{l}\text { Blinding? } \\
\text { All outcomes }\end{array}$ & Yes & $\begin{array}{l}\text { Article: "One dentist (Gerardo Pellegrino) } \\
\text {, not involved in the treatment of the pa- } \\
\text { tients, made all the clinical assessments } \\
\text { without knowing group allocation, there- } \\
\text { fore outcome assessor was blinded, however } \\
\text { Bio-Oss augmented sites could be identi- } \\
\text { fied on radiographs because they appeared }\end{array}$ \\
\hline
\end{tabular}

Interventions for replacing missing teeth: augmentation procedures of the maxillary sinus (Review) 
Felice 2009b （Continued)

more radio-opaque while Inion treated sites appeared rather radiolucent"

Incomplete outcome data addressed? $\quad$ Yes $\quad$ All data presented, no drop outs. All outcomes

Free of selective reporting?

Yes

All planned outcomes were reported.

Free of other bias?

Yes

Hallman 2002

Methods

Participants

Interventions

Outcomes
Randomised, split-mouth study, 1-year post-loading follow-up. No withdrawals

Patients having less than $5 \mathrm{~mm}$ of alveolar bone in the floor of the sinus. Adults treated at the Gävla Hospital, Gävla, Sweden. No specific exclusion criteria were given (unhealthy, systemic or local contraindications such as undergoing radiation therapy). 11 patients were treated in the split-mouth study and 10 in the preference group

Two-stage sinus lift with autogenous particulate bone from the mandibular ramus versus two-stage sinus lift with a mixture of $80 \%$ of bovine anorganic bone (Bio-Oss) and $20 \%$ of particulate bone from the mandibular ramus left to heal for 6 months. A fibrin glue (Tisseel Duo Quick, Immuno, Wien, Austria) was added to the grafts after thrombin (Thrombin, Immuno). A third group was composed by patients who refused to provide autogenous bone but accepted the treatment with a two-stage sinus lift with $100 \%$ Bio-Oss. For the latter group a resorbable porcine-derived collagen barrier (Bio-Gide, Geistlich Pharmaceutical) was used to cover the defect of sinus, and the healing time was prolonged to an average of 8.5 months (range: 8 to 9.5). Procedures were performed under local anaesthesia and oral sedation. All implants were turned titanium self tapping (Nobel Biocare, Göteborg, Sweden): Mark II type implants were used in the former two groups and Mark III in the latter. All patients were rehabilitated with screw-retained metal-ceramic fixed prostheses

Prosthesis and implant failure. Complications at the augmented and donor sites. Histomorphometrical evaluation

\section{Notes}

\section{Risk of bias}

\begin{tabular}{|c|c|c|}
\hline Item & Authors' judgement & Description \\
\hline Adequate sequence generation? & Yes & $\begin{array}{l}\text { Article: No information presented. } \\
\text { Author's reply: "The randomization was } \\
\text { done by a third party as a lottery. In an en- } \\
\text { velope there were } 12 \text { papers with either } 6 \\
\text { possibilities for the mixture to be on the left } \\
\text { side or the right side. Each patient was al- }\end{array}$ \\
\hline
\end{tabular}


Hallman 2002 (Continued)

lotted by picking up one paper which said mixture on the left or right side"

\begin{tabular}{|c|c|c|}
\hline Allocation concealment? & Yes & $\begin{array}{l}\text { Article: No information presented. } \\
\text { Author's reply: "The surgeon knew the out- } \\
\text { come of the surgery at the time of surgery } \\
\text { just before making the incision" }\end{array}$ \\
\hline $\begin{array}{l}\text { Blinding? } \\
\text { All outcomes }\end{array}$ & No & $\begin{array}{l}\text { Article: No information presented. } \\
\text { Author's reply: "The study was not } \\
\text { blinded". }\end{array}$ \\
\hline
\end{tabular}

Incomplete outcome data addressed? $\quad$ Yes $\quad$ All data presented, no drop outs.
All outcomes

Free of selective reporting? Yes

Free of other bias? $\quad$ Unclear

The study was supported by the producer of the bone substitute

Raghoebar 2005

Methods

Participants

Interventions
Randomised, split-mouth study, 2-year post-loading follow-up. No withdrawals

Patients with severely resorbed maxilla and reduced stability and retention of the upper denture. Adults treated at the University Hospital Groningen, The Netherlands. Patients were excluded if were edentulous for a period less than 1 year, history of irradiation in the head and neck area, history of reconstructive pre-prosthetic surgery or previous implant surgery. Five patients were treated

Two-stage sinus lift with autogenous blocks and particulate bone together with buccal onlays monocortico-cancellous bone grafts, to reconstruct the width of the maxilla, fixed with titanium screws harvested from the iliac crest with or without PRP left to heal for 3 months in a split-mouth trial. Barriers were not used. PRP was made using the Platelet Concentration Collection System kit (PCCS kit, 3i Implant Innovations Inc. Palm Beach Gardens, FL, USA). $54 \mathrm{ml}$ of blood were mixed with $6 \mathrm{ml}$ of anticoagulant (citrate dextrose) and processed with the platelet concentration system. To promote the release of growth factors from the platelets, $10 \%$ calcium chloride solution and the patient's serum, as a source of autologous thrombin, were added before actual reconstruction of the defect with the bone graft. The resulting gel was mixed with the bone graft and some gel was applied at the closure of the wound at the side treated with PRP. Three implants were inserted into the healed graft of each side and were left to heal for an additional 6 months. All the augmentation procedures were performed under general anaesthesia. Surgical templates were used to optimise implant insertion. All implants were turned titanium self tapping (Nobel Biocare, Göteborg, Sweden) and were rehabilitated with two implant-supported prostheses 
Raghoebar 2005 (Continued) $\begin{array}{ll}\text { Outcomes } & \begin{array}{l}\text { Prosthesis and implant failure. Complications at the augmented and donor sites. Histo- } \\ \text { morphometrical evaluation }\end{array}\end{array}$

Notes

Risk of bias

\begin{tabular}{|c|c|c|}
\hline Item & Authors' judgement & Description \\
\hline Adequate sequence generation? & Yes & $\begin{array}{l}\text { Article: No information presented. } \\
\text { Author's reply: "Randomisation by lot". }\end{array}$ \\
\hline Allocation concealment? & Unclear & $\begin{array}{l}\text { Article: No information presented. } \\
\text { Author's reply failed to clarify the issue. }\end{array}$ \\
\hline $\begin{array}{l}\text { Blinding? } \\
\text { All outcomes }\end{array}$ & Yes & $\begin{array}{l}\text { Article: "The investigators were blinded for } \\
\text { both the clinical and laboratory investiga- } \\
\text { tions with regard to the PRP-treated side" }\end{array}$ \\
\hline $\begin{array}{l}\text { Incomplete outcome data addressed? } \\
\text { All outcomes }\end{array}$ & Yes & All data presented, no drop outs. \\
\hline Free of selective reporting? & Yes & \\
\hline Free of other bias? & Unclear & $\begin{array}{l}\text { Author: "The apparatus was gift from the } \\
\text { company promoting the use of PRP" } \\
\text { This was considered to be irrelevant. } \\
\text { In all patients additional buccal onlays } \\
\text { were performed meaning that these pa- } \\
\text { tients might have not been the ideal candi- } \\
\text { dates for the hypothesis tested. It is there- } \\
\text { fore more difficult to interpret the results } \\
\text { since the role of the additional buccal on- } \\
\text { lays on the final outcome cannot be quan- } \\
\text { tified }\end{array}$ \\
\hline
\end{tabular}

Schaaf 2008

Methods

Randomised, split-mouth study with follow-up to abutment connection. No withdrawals. Data from patients treated according to a parallel group design were not provided or sought

Participants

Severe atrophy of the edentulous or partially edentulous posterior maxilla and intention to treat with onlay bone blocks and sinus floor augmentation. Residual bone height values appears to be in the range of 1 to $12 \mathrm{~mm}$ according to the measurements kindly provided by the authors. Adults treated at university clinics of Giessen and Herlangen (Germany). Patients were excluded if they had blood platelet disorders, haemorrhagic diathesis or medication with aspirin before surgery, infectious diseases such as hepatitis,

Interventions for replacing missing teeth: augmentation procedures of the maxillary sinus (Review) 
Schaaf 2008 (Continued)

malignancy, radiotherapy, severe osteoporosis, drug addition, and ineligibility to donate blood. 34 patients enrolled in the split-mouth study

Interventions

Two-stage sinus lift with lateral window approach using either autogenous particulate bone from the iliac crest alone or the same graft plus PRP. All sites were also horizontally augmented with corticospongeous blocks from the iliac crest fixed with screws. PRP was produced at the university Institutes of Clinical Immunology and Transfusion Medicine under transfusion medical standards. Autologous platelet concentrate from PRP derived from $450 \mathrm{ml}$ CPD-anticoagulated blood. The PRP was concentrated using differential centrifugation, then stored for $24 \mathrm{~h}$ and adjusted up to $10^{10}$ platelets $/ \mathrm{ml}$. The concentrations obtained were 11-12 times above the baseline level of whole blood. All augmentation procedures were performed under general anaesthesia. After 4 months of healing, different implant systems (no details provided) were inserted and left to heal submerged for 6 months

Outcomes

Implant failures. Complications at augmented sites. Histomorphometrical evaluation. Radiographic evaluation of bone height at the level of the former first molar at the lowest point of the sinus on panoramic radiographs taken pre-operatively, just after augmentation, and after implant placement. Bone density on CT scans taken 4 months after augmentation

Notes

Risk of bias

Item Authors' judgement $\quad$ Description

Adequate sequence generation? Yes

Author's reply: "Randomisation process has been performed by our department for medical statistics. They gave us a numbered randomisation data sheet. Every time we had a patient who fulfilled the inclusion criteria he got the next number on the list in strict sequence. The number on the list then told us in which group the patient has to be"

Allocation concealment?

Blinding?

Yes

No

All outcomes
Article: No information presented.

Author's reply: "The surgeon knows 1 day prior to the operation, when the study coordinator looked up the randomisation number"

Article: "Patients, as well as the immunologist involved in the PRP preparation and the examining pathologist, were blinded to the treatment"

Author's reply: "The outcome assessor was 
Incomplete outcome data addressed? No All outcomes
Not complete radiographic and data presented or supplied so we were unable to use part of the data

Free of selective reporting? Yes

Free of other bias? Unclear

In all patients additional buccal onlays were performed meaning that these patients might have not been the ideal candidates for the hypothesis tested. It is therefore more difficult to interpret the results since the role of the additional buccal onlays on the final outcome cannot be quantified

Szabó 2005

Methods

Participants

Interventions

Outcomes

Notes

Risk of bias
Randomised, split-mouth study with follow-up to implant loading. No withdrawals

Edentulous patients having less than $5 \mathrm{~mm}$ of alveolar bone in the floor of the sinus. Adults treated at university hospitals in Budapest (Hungary), Manchester (UK), Milan (Italy) and in a private practice in Bruges (Belgium). No specific exclusion criteria were given and patients were healthy and had no disease that might influence the treatment outcome. 20 patients enrolled

Two-stage sinus lift with autogenous particulate bone from the iliac crest versus two-stage sinus lift with 1.5 to $2 \mathrm{~g}$ beta-tricalcium phosphate (Cerasorb, Curasan AG, Kleinostheim, Germany) left healing for 6 months. In 10 of the 20 patients the alveolar crest was also widened with cortical bone blocks fixed with microscrews. No membranes were used to cover the bone. All the augmentation procedures were performed under general anaesthesia. Patients were instructed not to wear any dentures for 30 days. In 16 patients Ankylos (Degussa, Friadent, Germany) implants were used, whereas in four patients Protetim (Hungary) implants were used. The authors did no provide any explanation for using two different implant systems. Two implants were placed in each augmented sinus

Implant failure at abutment connection. Post-operative complications at the grafted site and at the donor site. Panoramic and computer tomographic imagines (CT images in 10 patients only) to provide a qualitative description of the consolidation of the grafts. Histomorphometrical assessment of cylindrical bone biopsies 


\begin{tabular}{|c|c|c|}
\hline Item & Authors' judgement & Description \\
\hline Adequate sequence generation? & Unclear & $\begin{array}{l}\text { Article: "The choice of sides was random- } \\
\text { ized using the coin-toss method" } \\
\text { One author from one of the centres replied: } \\
\text { "Centralised randomization with code in a } \\
\text { sealed envelope" }\end{array}$ \\
\hline Allocation concealment? & Unclear & $\begin{array}{l}\text { Article: No information presented. } \\
\text { One author from one of the centres replied: } \\
\text { "Sealed envelopes opened just before plac- } \\
\text { ing the graft into the sinus" }\end{array}$ \\
\hline $\begin{array}{l}\text { Blinding? } \\
\text { All outcomes }\end{array}$ & No & $\begin{array}{l}\text { Article: No information presented. } \\
\text { Author's reply: "No blinding was used". }\end{array}$ \\
\hline $\begin{array}{l}\text { Incomplete outcome data addressed? } \\
\text { All outcomes }\end{array}$ & No & No radiographic data presented. \\
\hline Free of other bias? & No & $\begin{array}{l}\text { Author informed us that they received free } \\
\text { bone substitutes. } \\
\text { This is considered to be irrelevant. } \\
\text { In } 10 \text { patients additional buccal onlays } \\
\text { were performed meaning that these pa- } \\
\text { tients might have not been the ideal candi- } \\
\text { dates for the hypothesis tested. It is there- } \\
\text { fore more difficult to interpret the results } \\
\text { since the role of the additional buccal on- } \\
\text { lays on the final outcome cannot be quan- } \\
\text { tified }\end{array}$ \\
\hline
\end{tabular}

Torres 2009

Methods

Randomised hybrid study design combining patients with a split-mouth study design with patients treated according to a quasi-random parallel group design with follow-up to 2 years after loading. No withdrawals

Participants

Patients having less than $7 \mathrm{~mm}$ of alveolar bone at the floor of the sinus. Adults treated at private clinic in Madrid, Spain. Exclusion criteria were severe systemic diseases (ASA score 3 or more), a previous history of chronic sinusitis. 57 patients were treated

Interventions

One or two-stage sinus lift procedures using a lateral window technique and 100\% granular Bio-Oss with or without PRP, left to heal for 6 months. Patients having up to $4 \mathrm{~mm}$ of residual bone height were augmented first and implant were placed after 6 months whereas patients with residual bone more than $4 \mathrm{~mm}$ up to $7 \mathrm{~mm}$ received implants during the sinus lift procedures. Implants were left to heal unloaded for 6 months. 10 to $20 \mathrm{cc}$ of venous blood were collected 30 minutes prior to the surgery and mixed with a $3.8 \%$ sodium citrate solution at a $5 / 1$ ratio, achieving anticoagulation 
Torres 2009 (Continued)

through calcium binding. The blood was then centrifuged into three and separated into three layers: red blood cells (RBCs), PRP and poor plasma. Flow cytometry was used for platelet counting. Platelets counts were $2.97 \pm 0.7$-fold over peripheral blood. PRP was activated with $30 \% \mathrm{CaCl}_{2}$ solution and a PRP gel was obtained and mixed with Bio-Oss. The entire bone of the buccal window was removed, and after the sinus was filled with the bone substitute no barrier was used to seal the windows. Patients were instructed not to wear their upper dentures for 2-3 weeks after surgery. Osseotite (Biomet 3I, Palm Beach, FL, USA) implants were used

Outcomes

Prosthetic and implant failures. Partial loss of the graft and complications. Histomorphometrical evaluation

Notes

Risk of bias

\begin{tabular}{|c|c|c|}
\hline Item & Authors' judgement & Description \\
\hline Adequate sequence generation? & Yes & $\begin{array}{l}\text { Article: "...randomized sequence was per- } \\
\text { formed by a computerized random number } \\
\text { generated using GraphPadQuickCalc soft- } \\
\text { ware (GraphPad Software Inc., La Joya, Ca, } \\
\text { USA), including the concealment of the al- } \\
\text { location schedule until the assignment was } \\
\text { done" }\end{array}$ \\
\hline Allocation concealment? & Yes & $\begin{array}{l}\text { Article: "Patients included in the inter- } \\
\text { patient clinical trial were allocated by a } \\
\text { blinded assistant into two groups: the first } \\
\text { was to be treated with ABB alone, and the } \\
\text { second with ABB + PRP" }\end{array}$ \\
\hline $\begin{array}{l}\text { Blinding? } \\
\text { All outcomes }\end{array}$ & Yes & $\begin{array}{l}\text { Article: "The surgeon was blinded to the } \\
\text { graft material applied to each patient be- } \\
\text { fore graft implantation. An assistant han- } \\
\text { dled PRP-ABB or the ABB group after the } \\
\text { surgeon had already accessed the sinus and } \\
\text { elevated membrane. The histologist was } \\
\text { blinded to the samples' groups throughout } \\
\text { the histomorphometric analysis" } \\
\text { Author's reply: "Implant stability was as- } \\
\text { sessed manually with removed prostheses } \\
\text { and mobile implants were considered as } \\
\text { failures and this evaluation was done by a } \\
\text { prosthodontist who was not aware of study } \\
\text { groups" }\end{array}$ \\
\hline
\end{tabular}

Incomplete outcome data addressed? Unclear All outcomes

We could only evaluate those data kindly provided by the authors 
Torres 2009 (Continued)

\begin{tabular}{|c|c|c|}
\hline Free of selective reporting? & Yes & \\
\hline Free of other bias? & No & $\begin{array}{l}\text { A mixed split-mouth and parallel group de- } \\
\text { sign was used: patients requiring augmen- } \\
\text { tation at bilateral sinuses were randomised } \\
\text { in a split-mouth study design whereas those } \\
\text { requiring unilateral sinus lift sinus were al- } \\
\text { ternated in a quasi-random study design. } \\
\text { We have not included data from the quasi- } \\
\text { random study }\end{array}$ \\
\hline
\end{tabular}

Wannfors 2000

Methods

Randomised trial of parallel group design, 3-year post-loading follow-up. No withdrawals at 3 years though three patients in the one-stage group refused consent to remove the prostheses for testing implant stability

Participants

Edentulous patients with more than $2 \mathrm{~mm}$ but less than $7 \mathrm{~mm}$ of residual bone under the maxillary sinuses. Adults treated under general anaesthesia at the Karolinska Hospital, Stockholm, Sweden. Patients were included if they were edentulous in the upper jaw. Patients were excluded if they were older than 80 years, had pathologies in the maxillary sinus, had bone diseases or took medications known to effect bone metabolism (i.e. corticosteroids and bisphosphonates). 40 patients enrolled, 20 in each group

Interventions

One-stage sinus lift with monocortical iliac bone blocks fixed usually with two implants left to heal for 6 months versus two-stage sinus lift with particulate bone from the iliac crest left to heal for 6 months and then usually two implants were inserted into the healed graft and were left to heal for an additional 6 months. All implants were titanium self tapping (Brånemark System, Nobel Biocare)

Outcomes

Prosthesis failure, implant failure and marginal bone level changes on intraoral radiographs taken with a paralleling technique at abutment connection, 1 and 3 years. Intraoperative sinus membrane perforations

Notes

Risk of bias

\begin{tabular}{|c|c|c|}
\hline Item & Authors' judgement & Description \\
\hline Adequate sequence generation? & Unclear & $\begin{array}{l}\text { Article: "He (patient) was allotted to one } \\
\text { of the two treatments according to a previ- } \\
\text { ously designed scheme by a third person" } \\
\text { Author's reply: "The randomization was } \\
\text { performed by a third person without any } \\
\text { beforehand contact with the patients" }\end{array}$ \\
\hline
\end{tabular}

Interventions for replacing missing teeth: augmentation procedures of the maxillary sinus (Review) 
Wannfors 2000 (Continued)

\begin{tabular}{|c|c|c|}
\hline Allocation concealment? & Unclear & $\begin{array}{l}\text { Article: No information presented. } \\
\text { Author's reply failed to clarify the issue. }\end{array}$ \\
\hline $\begin{array}{l}\text { Blinding? } \\
\text { All outcomes }\end{array}$ & No & $\begin{array}{l}\text { Article: No information presented. } \\
\text { Author's reply: "The outcome assessor had } \\
\text { knowledge of the randomized group, how- } \\
\text { ever not when assessing the x-ray data" }\end{array}$ \\
\hline $\begin{array}{l}\text { Incomplete outcome data addressed? } \\
\text { All outcomes }\end{array}$ & No & Full data of complications not provided. \\
\hline Free of selective reporting? & No & Full data of complications not provided. \\
\hline Free of other bias? & Yes & \\
\hline
\end{tabular}

PRP - platelet-rich plasma

Characteristics of excluded studies [ordered by study ID]

\begin{tabular}{|c|c|}
\hline Study & Reason for exclusion \\
\hline Aimetti 2008 & $\begin{array}{l}\text { The article presented data from four patients treated following a split-mouth design. Authors informed us that } \\
\text { they actually treated } 16 \text { patients. We are unable to present the data for the remaining } 12 \text { patients }\end{array}$ \\
\hline Barone 2005 & No clinical outcome measures related to implant treatment. \\
\hline Barone 2008 & Insufficient follow-up time with no clinical outcome measures related to implant treatment \\
\hline Boyne 2005 & $\begin{array}{l}\text { Described as RCT, unclear number of patients, unequal number of patients in the treatment groups. No reply to } \\
\text { letter }\end{array}$ \\
\hline Choi 2009 & No clinical outcome measures related to implant treatment. \\
\hline Consolo 2007 & No clinical outcome measures related to implant treatment. \\
\hline Cordaro 2008 & No clinical outcome measures related to implant treatment. \\
\hline Crespi 2009 & No clinical outcome measures related to implant treatment. \\
\hline Froum 1998 & $\begin{array}{l}\text { Described as RCT, unclear number of patients and tested interventions which seem to be much more than eight, } \\
\text { unequal number of patients in the treatment groups. No reply to letter }\end{array}$ \\
\hline Froum 2006 & No clinical outcome measures related to implant treatment. \\
\hline
\end{tabular}


(Continued)

Froum $2008 \quad$ No clinical outcome measures related to implant treatment.

Hallman 2008 No clinical outcome measures related to implant treatment.

Kassolis $2005 \quad$ No clinical outcome measures related to implant treatment.

Kim 2009 No clinical outcome measures related to implant treatment.

Mangano 2007 The authors informed us that the trial was not an RCT but a CCT

Steigmann 2005 No clinical outcome measures related to implant treatment.

Suba $2006 \quad$ No clinical outcome measures related to implant treatment.

Tawil $2001 \quad$ Inappropriate study design, neither parallel group nor split-mouth

Triplett 2009 Unclear how many patients were randomised to each group, data very confused and we were unable to retrieve sufficient data from the original publication. No reply to letter

CCT - controlled clinical trial

RCT - randomised controlled clinical trial 